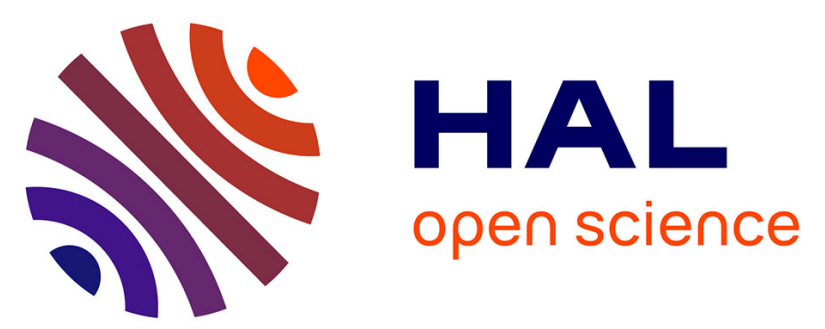

\title{
Comparative study of vapour-liquid equilibrium and density modelling of mixtures related to carbon capture and storage with the SRK, PR, PC- SAFT and SAFT-VR Mie equations of state for industrial uses
} Alfonso Gonzalez Perez, Christophe Coquelet, Patrice Paricaud, Antonin Chapoy

\section{To cite this version:}

Alfonso Gonzalez Perez, Christophe Coquelet, Patrice Paricaud, Antonin Chapoy. Comparative study of vapour-liquid equilibrium and density modelling of mixtures related to carbon capture and storage with the SRK, PR, PC- SAFT and SAFT-VR Mie equations of state for industrial uses. Fluid Phase Equilibria, 2017, 440, 10.1016/j.fluid.2017.02.018 . hal-01487723

\section{HAL Id: hal-01487723}

https://hal-mines-paristech.archives-ouvertes.fr/hal-01487723

Submitted on 13 Mar 2017

HAL is a multi-disciplinary open access archive for the deposit and dissemination of scientific research documents, whether they are published or not. The documents may come from teaching and research institutions in France or abroad, or from public or private research centers.
L'archive ouverte pluridisciplinaire HAL, est destinée au dépôt et à la diffusion de documents scientifiques de niveau recherche, publiés ou non, émanant des établissements d'enseignement et de recherche français ou étrangers, des laboratoires publics ou privés. 


\section{Comparative study of vapour-liquid equilibrium and density modelling of mixtures related to carbon capture and storage with the SRK, PR, PC- SAFT and SAFT-VR Mie equations of state for industrial uses}

Alfonso Gonzalez Perez ${ }^{\mathrm{a}, \mathrm{b}}$, Christophe Coquelet $^{\mathrm{b}}$, Patrice Paricaud ${ }^{\mathrm{b}, \mathrm{c}}$ and Antonin Chapoy ${ }^{\mathrm{a}, \mathrm{b}^{*}}$

${ }^{a}$ Hydrates, Flow Assurance \& Phase Equilibria Research Group, Institute of Petroleum Engineering, Heriot-Watt University, Edinburgh, EH14 4AS, UK

${ }^{b}$ MINES ParisTech PSL Research University, CTP-Centre of Thermodynamics of Processes, 35 Rue Saint Honoré, 77305 Fontainebleau, France

${ }^{c}$ UCP, ENSTA ParisTech, Université Paris-Saclay, 828 Boulevard des Maréchaux, 91762 Palaiseau cedex, France.

* Corresponding Author: Antonin Chapoy (antonin.chapoy@pet.hw.ac.uk)

\section{Abstract}

Carbon capture and storage (CCS) is nowadays considered as one of the most promising methods to counterbalance the $\mathrm{CO}_{2}$ emissions from the combustion of fossil fuels, natural gas processing, cement manufacturing, etc. In dealing with the transport and the storage of $\mathrm{CO}_{2^{-}}$ rich streams, design of a safe and optimum process requires the knowledge of thermophysical properties (especially density) of $\mathrm{CO}_{2}$-rich mixtures. Consequently, the development of accurate thermodynamic models to evaluate these properties plays a key role in the context of CCS. This work is focused on comparing the capability of four Equations of State (EoSs) in modelling the Vapour-Liquid Equilibrium (VLE) and the density of binary mixtures of interest in the field of CCS. Two Cubic EoSs (CEoS), the original Soave-Redlich-Kwong (SRK) and Peng-Robinson (PR) EoSs, and two Statistical Associating Fluid Theory-based EoSs, namely the Perturbed Chain (PC-SAFT) EoS and the Variable Range SAFT-VR Mie EoS have been considered. These EoSs were compared (with both zero and regressed binary interaction parameters) with respect to VLE and density data of 108 binary mixtures of five main gaseous components $\left(\mathrm{CO}_{2}, \mathrm{CH}_{4}, \mathrm{C}_{2} \mathrm{H}_{6}, \mathrm{~N}_{2}\right.$, and $\left.\mathrm{H}_{2} \mathrm{~S}\right)$. Concerning the cubic EoS, the Peneloux volume translation was used to better correlate densities. The comparison reveals that on average the most accurate VLE and density predictions are obtained with the SAFTbased EoSs, while similar results in VLE calculations are obtained with the four EoSs when regressed binary interaction parameters are used. The SAFT-VR Mie EoS is on average more accurate for the description of VLE and density data than the other studied models. 


\section{Introduction}

Carbon Capture and Storage (CCS) has been proposed as a potential method to mitigate climate change. Carbon storage may allow continued combustion of fossil fuels in power stations preventing $\mathrm{CO}_{2}$ emissions to the atmosphere and covering the electricity demand in conjunction with other zero-emissions technologies (renewable resources and nuclear power plants) [1]. However, power stations are not the only source of $\mathrm{CO}_{2}$ which can be fitted with carbon capture technologies; many other industrial processes also produce large amounts of $\mathrm{CO}_{2}$, such as cement manufacturing or natural gas treatment, where the $\mathrm{CO}_{2}$ is also emitted along significant amount of $\mathrm{H}_{2} \mathrm{~S}$.

CCS incorporates a large number of technologies and processes, such as combustion methods, transportation pipelines, and injection systems. Thus, under this framework, the selection of a predictive thermophysical property model is of principal importance. The development of accurate thermodynamic models to predict thermophysical properties is required for the design of a safe and optimum $\mathrm{CO}_{2}$-rich steams transport and storage system. These thermodynamic models or equations of state (EoSs) should accurately predict phase diagrams and the densities of the coexisting phases far and close to the supercritical region.

Several thermodynamic models have been used in the literature to predict the phase behaviour and densities of $\mathrm{CO}_{2}$-rich systems and reservoir fluids. Countless EoSs have been proposed and have evolved since Clapeyron [2] proposed the Ideal Gas (IG) law in 1834. Next milestone in the history of EoS was the van der Waals (vdW) EoS (1873) which is the beginning of the cubic equations of state $(\mathrm{CEOS})$ [3]. Although the vdW equation of state was the first EoS that considered a pairwise attractive intermolecular force, there has not been any significant improvement of CEoS until Redlich and Kwong revised the van der Waals EoS in 1949. In the 1970's, Soave proposed a modification known as the Soave-Redlich-Kwong (SRK) EoS [4], which allowed better descriptions of pure component vapour pressures, while Peng and Robinson (PR) [5] later developed another EoS based on the vdW equation, which improved the poor saturated liquid density description of SRK EoS [6] for hydrocarbons. These two equations combine simplicity and reasonable accuracy, and give accurate results for mixtures of non-polar fluids; for this reason the SRK and PR EoSs had rapidly gained acceptance by the hydrocarbon industry. CEoS are probably the most-widely employed EoSs in thermodynamics [7] and, because of this, many modifications have been proposed. Thus, for the purpose of improving the cubic EoSs, different functional terms or additional parameters were proposed, e.g. the Peneloux volume translation [8] which provides better 
liquid densities calculations [9]. However, despite the success of cubic EoSs, the accuracy of these equations decreases when predicting the behaviour of substances that form strong association (hydrogen bonding) between molecules, as classical EoS were developed by considering only the van der Waals dispersion forces [10]. Therefore, in order to improve the CEoS for associating fluids, it was necessary to add some contributions to the perturbation expansion of the free energy according to the thermodynamic perturbation theory (TPT) of Wertheim. Chapman et al. [11] derived the Statistical Associating Fluid Theory (SAFT) equation of state by applying Wertheim's TPT and extending it to mixtures. Many modifications of the SAFT-based EoSs were suggested over the years, such as CK-SAFT [12], Lennard-Jones SAFT (LJ-SAFT) [13], variable range SAFT (SAFT-VR) [14], softSAFT [15] and perturbed-chain SAFT (PC-SAFT) [16] [17]. According to perturbation theory, the idea behind the statistical theory is to split the Helmholtz free energy in several contributions. Each SAFT version is different depending on the interaction pair potential between the segments (square-well, Lennard-Jones, Mie, etc) and the approach used to calculate the contributions (hard sphere, chain, association, etc). By applying Wertheim's TPT, the Cubic Plus Association EoS (CPA) [18] was developed by combining the simplicity of a cubic equation of state (SRK) and the TPT employed for the association part.

In upstream operations, there has been little interest amongst the oil and gas industry to look for more accurate EoS, considering that in reservoir simulations the cubic EoSs provide enough accuracy due to uncertainties in the geology and the flow in porous media. Likewise, considering the computational time, thanks to their simplicity, cubic EoSs are scarcely replaced by more complex PVT models in reservoir simulations. However in the downstream industry and CCS, more sophisticated thermodynamic models can be applied in order to increase the accuracy of the PVT modelling: for example SAFT-like EoSs can provide a better density description at high pressures and high temperatures (HPHT) [19]. Then, despite that PC-SAFT has been implemented in some commercial software and used in asphaltene precipitation modelling, the SAFT-based EoS are still less matured in PVT modelling than the SRK or PR EoS [19].

In this work, two CEoS and two SAFT-based EoSs are used to model vapour-liquid equilibria (VLE) and densities of 108 binary mixtures of the main compounds of flue gas and reservoir fluids, leaving aside the associating compounds, i.e. water. The studied systems are binary mixtures of $\mathrm{CO}_{2}, \mathrm{CH}_{4}, \mathrm{C}_{2} \mathrm{H}_{6}, \mathrm{~N}_{2}$ and $\mathrm{H}_{2} \mathrm{~S}$ with alkanes, the typical flue gases $\left(\mathrm{O}_{2}, \mathrm{Ar}, \mathrm{CO}\right.$ and $\mathrm{SO}_{2}$ ) and aromatics. The assessed models are the classical PR and SRK CEoS, the wellknown PC-SAFT EoS and one of the latest versions of the family of SAFT equations, the 
SAFT-VR Mie EoS [6] [20]. This study focuses on non-associating compounds. Here, a nonassociating model for $\mathrm{H}_{2} \mathrm{~S}$ with the PC-SAFT and SAFT-VR Mie EoSs has been considered, although $\mathrm{H}_{2} \mathrm{~S}$ has been described by Dufal et al. [21] using a $4 \mathrm{C}$ association model with SAFT-VR Mie. Note also that Diamantonis et al. $\mathrm{H}_{2} \mathrm{~S}$ [22] found that considering $\mathrm{H}_{2} \mathrm{~S}$ as an associating-compound is slightly less accurate using the PC-SAFT EoS for describing the VLE of systems such as $\mathrm{CO}_{2}-\mathrm{H}_{2} \mathrm{~S}$.

Furthermore, the models used are briefly presented, especially the SAFT-based EoSs. The results of the comparison between the cubic and SAFT EoSs are then presented in two parts corresponding to the descriptions of binary VLE and density data. A large amount of data was collected from the literature: experimental data (binary VLE and single-phase fluid densities) and reliable correlations (pure component densities). In order to make a fair comparative study, the four models have been treated following the same procedure and using the same set of data for fitting the temperature-independent binary interaction parameters (BIP).

\section{Thermodynamic models}

\subsection{Cubic Equations of State}

An EoS is a thermodynamic analytical expression describing the state of matter and relating pressure $(P)$, temperature $(T)$ and molar volume $(v)$. Most of the CEoS are pressure-explicit equations and once they are solved for volume (or density), other properties, such as fugacity or chemical potential, can be obtained from thermodynamic relations [22] [23]. The cubic family of EoSs are based on a cubic dependence on the volume with two parameters, $a$ and $b$; and a temperature-dependant function which can be correlated to experimental data (vapour pressure). CEoS can be expressed by this general formula [24]:

$$
P=\frac{R T}{v-b}-\frac{a \alpha(T)}{v^{2}+u v b+w b^{2}}
$$

where $R$ is the ideal gas constant, $a$ and $b$ are the parameters of the EoS calculated using the critical temperature $\left(T_{c}\right)$ and pressure $\left(P_{c}\right)$ of each component; $\alpha(T)$ is a function of temperature, acentric factor, $T_{c}$ and $P_{c}$. SRK and PR are the CEoS considered in this work, $u$ and $w$ are constants, and their values are $u=1$ and $w=0$ for SRK and $u=2$ and $w=-1$ for PR.

In this work, the original expression for the $\alpha$ function was used, proposed by Soave [4] for the SRK EoS, and that of Peng and Robinson [25] for the PR EoS. No pure component 
parameters were adjusted. In order to extend the CEoS to multicomponent systems, the standard van der Waals mixing rules were used, i.e.:

$$
\begin{aligned}
& b=\sum_{i} x_{i} b_{i} \\
& a=\sum_{i} \sum_{j} x_{i} x_{j} \sqrt{a_{i} a_{j}}\left(1-k_{i j}\right)
\end{aligned}
$$

where $x_{i}$ and $x_{j}$ are the composition of pure components $i$ and $j$, and $k_{i j}$ the binary interaction parameter (BIP). The BIPs are coefficients introduced to better describe the experimental phase behaviour.

In general, liquid densities tend to be underestimated by the SRK and PR CEoS [26]. To improve the density predictions of dense fluid phases, volume translations can be used. The Peneloux volume correction (VC) [8] has been implemented herein (Equation 4) and the results with and without Peneloux shift parameters are discussed in the Section 3.2.

$$
V=V^{E O S}+\sum_{i}^{N C o m p} x_{i} V_{i}^{c}
$$

where $V^{E o S}$ is the molar volume calculated by the SRK and PR EoSs and $V^{c}{ }_{i}$ the volume correction parameter. The volume translation parameters have been treated as temperature independent [8]. The liquid density calculations are improved by the use of temperaturedependent parameters for the volume corrections; however the use of temperature-dependent parameters has greater influence on derivative thermodynamic properties, such as heat capacities $\left(\mathrm{c}_{\mathrm{v}}\right.$ and $\left.\mathrm{c}_{\mathrm{p}}\right)[27]$.

\subsection{SAFT Equations of State}

SAFT - like EoSs are based on perturbation theories [11]. They are expressed in terms of the reduced Helmholtz energy and as a sum of several contributions corresponding to the free energy of the reference fluid and the various perturbation terms (Eqs. 5 and 6). The PC-SAFT model was developed by considering the hard chain fluid as the reference system and applying the perturbation theory of Barker and Henderson [28] [29]. The SAFT-VR Mie is a reformulation of the variable range SAFT-VR EoS and incorporates the third order term of Barker and Henderson perturbation expansion [6].

PC-SAFT: $\frac{A^{\text {RESIDUAL }}}{N k_{b} T}=\frac{A^{\text {HARD-CHAIN }}}{N k_{b} T}+\frac{A^{\text {DISPERSION }}}{N k_{b} T}$ 
SAFT-VR Mie: $\frac{A^{\text {RESIDUAL }}}{N k_{b} T}=\frac{A^{\text {MONOMER }}}{N k_{b} T}+\frac{A^{\text {CHAIN }}}{N k_{b} T}$

One of the most important differences between the SAFT-VR Mie and PC-SAFT EoSs is the pair potential considered. Concerning the PC-SAFT EoS, the modified square well pair potential (Eq. 7), suggested by Chen and Kreglewski [30] is applied to compute the effective hard sphere diameter, while the Lennard-Jones (LJ) potential was used for the dispersion term.

$u(r)= \begin{cases}\infty & r<\left(\sigma-s_{1}\right) \\ 3 \varepsilon & \left(\sigma-s_{1}\right) \leq r<\sigma \\ -\varepsilon & \sigma \leq r<\alpha \sigma \\ 0 & r \geq \alpha \sigma\end{cases}$

Concerning the SAFT-VR Mie EoS, the pair potential is the Mie potential that is a generalized version of the LJ potential. The Mie pair potential has two additional adjustable parameters (repulsive and repulsive exponents, $\lambda_{\mathrm{r}}$ and $\lambda_{\mathrm{a}}$ ) that allow for a better description of derivative thermodynamic properties [20]. The Mie potential is given by

$u(r)=\frac{\lambda_{r}}{\lambda_{r}-\lambda_{a}}\left(\frac{\lambda_{r}}{\lambda_{a}}\right)^{\frac{\lambda_{r}}{\lambda_{r}-\lambda_{a}}} \varepsilon\left(\left(\frac{\sigma}{r}\right)^{\lambda_{r}}-\left(\frac{\sigma}{r}\right)^{\lambda_{a}}\right)$

In both Eqs. (7) and (8), $u(r)$ is the pair potential between segments, $r$ the radial distance, $\sigma$ the segment diameter and $\varepsilon$ the depth of potential well. In Eq. (7), $\alpha$ is the reduced well width and a ratio of $s_{1} / \sigma=0.12$ is assumed [16].

The PC-SAFT and SAFT-VR Mie pure-component parameters used in this work are taken from the literature [6] [17] [31] [32] [33]. Another difference between these EoSs is the number of parameters regressed by fitting pure component data. For non-associating components, the PC-SAFT model requires three parameters: the segment number $(m)$, the segment diameter $(\sigma)$ and the segment energy $(\varepsilon)$. For the SAFT-VR Mie EoS, besides the traditional SAFT parameters $m, \sigma$ and $\varepsilon$, two extra parameters are required to describe the Mie potentials $\left(\lambda_{r}\right.$ and $\lambda_{a}$ ), although it is common to fix $\lambda_{a}$ to 6 . The used molecular parameters for the PC-SAFT EoS from the literature are fitted to vapour pressure and saturated liquid density, while the SAFT-VR Mie parameters are regressed using in addition condensed-liquid density and speed of sound data points [20]. 
As the SAFT-VR Mie EoS is a relatively recent EoS, there are no published parameters for the long chain alkanes. Hence, in order to avoid fitting the parameters for each compound, the molecular parameters for the series of $n$-alkanes have been correlated with respect to the molecular weight $\left(M_{w}\right)$ following a similar procedure as Pedersen et al. for PC-SAFT [34]. It has been found that the number of segments $m$ increases linearly with molecular weight $M_{w}$ for long-chain alkanes. Thus, from a least squares analysis, $m$ and $M_{w}$ can be related using Eq. (9). However to correlate the diameter and energy of the segment, as well as the Mie repulsion exponent, the linear dependence is between the $M_{w}$ and the product of $m \sigma, m \varepsilon / k_{b}$ and $m \lambda_{\mathrm{r}}$ (Eqs. 10-12). In Figure 1, these correlations are plotted together with the coefficients of determination $\left(R^{2}\right)$ from the least squares analysis.

$$
\begin{aligned}
& m=0.01357 \mathrm{M}_{\mathrm{W}}+1.0324 \\
& m \sigma=0.07278 \mathrm{M}_{\mathrm{w}}+3.2699 \\
& m \varepsilon / \mathrm{k}_{\mathrm{b}}=8.0315 \mathrm{M}_{\mathrm{w}}+52.044 \\
& m \lambda_{\mathrm{r}}=0.3723 \mathrm{M}_{\mathrm{w}}+4.3413
\end{aligned}
$$

Once the pure compound parameters are determined, binary interaction parameters (BIPs) can be adjusted against vapour-liquid equilibrium data of mixtures. The BIPs are coefficients introduced to correct the combining rules for the unlike attractive dispersive energy $\left(\varepsilon_{i j}\right)$ [35]. The conventional Berthelot-Lorentz combining rule has been used (Eq.13) [16] in the PCSAFT EoS, while the SAFT-VR Mie model uses a specific geometric relation defined by Eq.14 [20].

$$
\begin{aligned}
& \varepsilon_{i j}=\left(1-k_{i j}\right) \sqrt{\varepsilon_{i} \varepsilon_{j}} \\
& \varepsilon_{i j}=\left(1-k_{i j}\right) \frac{\sqrt{\sigma_{i}^{3} \sigma_{j}^{3}}}{\sigma_{i j}^{3}} \sqrt{\varepsilon_{i} \varepsilon_{j}}
\end{aligned}
$$

where $k_{i j}$ is the binary interaction parameter (BIP) and $\sigma_{i}$ the segment diameter of compound $i$. The combining rule used to calculate $\sigma_{i j}$ is given by

$$
\sigma_{i j}=\frac{\sigma_{i}+\sigma_{j}}{2}
$$

\section{Results and discussion}


108 binary systems of 29 typical components in flue gases and reservoir fluids were considered in this study. The selected components are 7 gases $\left(\mathrm{CO}_{2}, \mathrm{~N}_{2}, \mathrm{O}_{2}, \mathrm{Ar}, \mathrm{H}_{2} \mathrm{~S}, \mathrm{CO}\right.$ and $\mathrm{SO}_{2}$ ), 20 alkanes and 2 aromatics (benzene and toluene). A summary of the VLE and density data available in the literature for the studied binary mixtures is presented in Table 1 . This comparative analysis has included a large number of experimental data sets collected from the literature. All data sets collected are included in the NIST Databases [36] [37]. However, many of the PVT data collected have not been used in order to avoid wrong calculations (i.e. VLE points close to the critical point) or because they were not consistent (i.e. data points not following the trend of the isotherm and data sets with lack of consistency between isotherms or other authors). In total, 22904 VLE and 26479 density experimental data points of binary mixtures have been used in this work. In addition, 31928 single phase densities of pure components have been obtained from correlations and EoSs.

The comparative study is divided into two parts: phase equilibrium and density calculations. For the phase equilibrium, bubble point pressures and vapour phase compositions are predicted with zero binary interaction parameters $\left(k_{i j}=0\right)$. BIPs are then regressed on the VLE data for each binary mixture. In order to do a fair comparison between EoSs, the regression was done by treating the $k_{i j}$ 's as temperature independent. The BIPs have been regressed by minimizing the objective function given in Eq. 16, which is the sum of the deviations between the calculated bubble point pressures and the experimental VLE data. Subsequently, the deviations in the bubble point calculations were again determined for each model using the regressed $k_{i j}$ 's.

The second part of the study is focused on density calculations. Firstly, the densities of pure components are predicted and compared against the correlated data from the literature. Secondly, the densities of binary systems are calculated and also compared against the compiled experimental density data. The $k_{\mathrm{ij}}$ values regressed on bubble points were used for predicting densities and the volume-translation concept within the framework of CEoS was also considered.

$$
\min F=\frac{100}{N} \sum_{1}^{N}\left(\frac{\left|P_{b u b b l e}^{\text {exp }}-P_{b u b b l e}^{\text {cal }}\right|}{P_{\text {bubble }}^{\text {exp }}}\right)
$$

The modelling results are assessed by comparing the average deviations (\%AAD) between the models and the experimental data. The AAD is the average absolute deviation and is defined as 
$A D D(\%)=\frac{1}{N} \sum_{i=1}^{N}\left(\left|X^{\exp }-X^{E o S}\right| / X^{\exp }\right) \cdot 100$

where $X$ is the evaluated property (bubble pressure, vapour mole fraction or density), $N$ is the number of data, the exp and $E o S$ exponents denote the experimental data and the calculations from the equation of state, respectively.

\subsection{VLE calculations}

The Mie molecular parameters of the $n$-alkanes series were correlated to the molecular weights. Then, before introducing the VLE results, the vapour pressure of $n \mathrm{C}_{14}, n \mathrm{C}_{16}, n \mathrm{C}_{18}$, $n \mathrm{C}_{24}$ and $n \mathrm{C}_{32}$ were studied using the correlated parameters (Figure 2). At reduced temperatures $\left(T_{r}=T / T_{c}\right)$ between of $0.5<T_{r}<0.9$, the average absolute deviation of the calculated vapour-pressure is $5.8 \%$. However the VLE calculations for the systems containing long $n$-alkanes are performed at temperatures that can be considered around $0.7 \mathrm{~T}_{\mathrm{r}}$. Therefore the average deviation in the saturation pressure of the long-chain alkanes is $1.95 \%$, and is similar to the \%AAD of the description of saturation pressure of the $n$-eicosane using fitted parameters from the literature, $1.83 \%$.

The phase equilibrium study is divided in five parts, according to the main five gaseous components considered in this work: $\mathrm{CO}_{2}, \mathrm{CH}_{4}, \mathrm{C}_{2} \mathrm{H}_{6}, \mathrm{~N}_{2}$ and $\mathrm{H}_{2} \mathrm{~S}$. Due to the large number of considered systems, several types of phase diagrams have been found. According to the Scott and van Konynenburg classification [38], the phase diagrams of the studied systems are classified as type $\mathrm{I}$ (e.g. $\mathrm{CH}_{4}-\mathrm{CO}_{2}, \mathrm{C}_{2} \mathrm{H}_{6}-\mathrm{H}_{2} \mathrm{~S}, \mathrm{CO}_{2}-\mathrm{O}_{2}$ [39]), type II (e.g. $\mathrm{CO}_{2}-n$-octane, $\mathrm{CO}_{2}-n$-decane [40]), type III (e.g. $\mathrm{CO}_{2}+$ longer $n$-alkanes than $\mathrm{C}_{14}$ [41] or $\mathrm{CH}_{4}-\mathrm{H}_{2} \mathrm{~S}$ [42]) and type $\mathrm{V}$ (e.g. $\mathrm{CH}_{4}-n$-hexane [43]). Despite the different temperature ranges and number of experimental data available, all the studied systems were treated equally, i.e. special treatments in favour of a particular model was avoided in order to do a relevant comprehensive evaluation of the four models.

Firstly, the VLE results of modelling the $\mathrm{CO}_{2}$ binary systems are presented in Table 2. The experimental VLE data for 27 mixtures of $\mathrm{CO}_{2}$ over a broad range of temperatures were modelled using the SRK, PR, PC-SAFT and SAFT-VR Mie EoSs. In general, the four studied models lead to similar results for the phase equilibrium predictions $\left(k_{i j}=0\right)$ and calculations $\left(k_{i j} \neq 0\right)$, with \%AAD averaging approximately $15 \%$ and $4.3 \%$ respectively. It has been observed that the deviations of the SRK model are similar to those reported for the PR EoS, as well as the BIPs regressed for each studied system. However, comparing both SAFT EoSs, a 
slight difference can be seen between the regressed $k_{i j}$ values. The $k_{i j}$ values for the $\mathrm{CO}_{2}+n$ alkanes systems and their trend are plotted in Figure 3.

The SAFT-VR Mie EoS is on average the model which predicts the VLE of $\mathrm{CO}_{2}$ systems with the lowest \%AAD to experimental data. Both CEoS models better describe the phase equilibrium of the mixtures of $\mathrm{CO}_{2}$ with gases $\left(\mathrm{N}_{2}, \mathrm{O}_{2}, \mathrm{Ar}, \mathrm{H}_{2} \mathrm{~S}, \mathrm{CO}\right.$ and $\left.\mathrm{SO}_{2}\right)$ and aromatic compounds (benzene and toluene); while the SAFT-based EoSs better performed for the $\mathrm{CO}_{2}$ + alkanes systems.

Special mention is made in Figure 4 about the $\mathrm{CO}_{2}+\mathrm{N}_{2}$ system due to the very poor predictions done by the CEoS and SAFT-VR Mie EoS. In the Figure 4a, it can be observed that the PC-SAFT EoS predicts $\left(\mathrm{k}_{\mathrm{ij}}=0\right)$ with reasonable accuracy this system. The SRK and PR models underestimate the bubble point pressure, while it is overestimated by the SAFTVR Mie EoS. Consequently, in Figure 4b, the four models similarly describe the phase equilibria by using fitted BIPs.

The average absolute deviation in the bubble point pressures and vapour-phase compositions for the $\mathrm{CH}_{4}+\mathrm{Comp} 2$ binary systems predicted by the four studied models are presented in Table 3, as well as the regressed $k_{i j}$ values and model deviations in the VLE calculations. The SAFT-VR Mie model presents the best predictive capability $\left(9.9 \%\right.$ in $\Delta P^{\text {bubble }}$ against the $12.8 \%$ of PR EoS), the four studied models report comparable AADs around $4.5 \%$ using the fitted independent temperature BIP. In Figure 5, the phase diagram of the $\mathrm{CH}_{4}+\mathrm{CO}_{2}$ system is performed as an example of the good agreement between the CEoS and VLE data for such type of systems.

In Table 4, the results for the $\mathrm{C}_{2} \mathrm{H}_{6}+$ Comp2 systems are reported. One can observe that the lowest deviations between predicted $\left(k_{i j}=0\right)$ and experimental VLE data of these binary systems containing ethane were obtained in general with CEoS. It is worth noting the high deviation in the vapour-phase composition for ethane + gases binary systems reported by all the models, with AADs around $21 \%$ for predicted and $12 \%$ for calculated $\Delta y_{1}$. Such high deviations in the vapour composition may be explained by the low miscibility of ethane in the vapour phases which leads to high relative errors, as depicted for example for the $\mathrm{C}_{2} \mathrm{H}_{6}+$ Ar system in Figure 6.

The SAFT-VR Mie EoS is the best model for predicting the VLE of nitrogen + Comp2 binary mixtures; however, these mixtures are the only systems which, on average, are better predicted by the cubic equations of state using the regressed BIP (Table 5). An example 
which illustrates this is the phase equilibria of the $\mathrm{N}_{2}+\mathrm{H}_{2} \mathrm{~S}$ system performed in Figure 7, where it can be seen that the SAFT-VR Mie model better predicts the VLE data, although, by using regressed $k_{i j}$ values, the PR EoS describes this system slightly better than the SAFT-like EoS.

Finally, the VLE results of modelling the $\mathrm{H}_{2} \mathrm{~S}+$ Comp2 binary systems are reported in Table 6. As with the previously presented $\mathrm{CO}_{2}$, methane and ethane mixtures, the model that better performs for hydrogen sulphide binary systems is the SAFT-VR Mie EoS. Hydrogen sulphide was modelled as a non-associating molecule and the results from the SAFT-based EoSs are in good agreement with VLE data of the $\mathrm{H}_{2} \mathrm{~S}+$ Comp2 systems, although better results are expected when modelling the $\mathrm{H}_{2} \mathrm{~S}$ as an associating compound.

A summary of the VLE results is reported in Table 7. The deviation of each collection of mixtures is presented, divided into four groups: gases, alkanes, aromatics and average. The overall deviations of the four models are also provided in this table. It can be first concluded that the cubic equations of state and the SAFT models have comparable predictive capabilities (\%AAD around $14 \%$ in $\Delta P^{\text {bubble }}$ and $5 \%$ in $\Delta y_{1}$ ) and similar results in VLE calculations using the regressed BIP (approximately $4.8 \%$ in $\Delta P^{\text {bubble }}$ and $3.1 \%$ in $\Delta y_{1}$ ) were obtained for all models. Nevertheless, in general, the SAFT-VR Mie EoS predicts $\left(k_{i j}=0\right)$ and describes (using the fitted BIPs) the phase equilibria of the 108 binary systems slightly better than the other three studied EoSs. Focusing our attention on the groups of compounds, it can be highlighted that the SAFT-based EoSs allow for the lowest deviations on the description of systems containing alkanes, while both CEoS perform better for mixtures containing gaseous components as well as the aromatic compounds. If the two cubic models are compared, despite the high level of similarity, it can be concluded that, on average, the SRK EoS better predicts the phase behaviour of the studied systems with $k_{i j}=0$, while the PR EoS reports lower deviations on the VLE calculations, when $k_{i j} \neq 0$. In general, the PC-SAFT EoS leads to higher average deviations, especially for the mixtures with gases and aromatics. Nonetheless, as previously mentioned, the PC-SAFT model outperformed the CEoS for the systems containing alkanes. This is because the PC-SAFT EoS is a hard-chain reference fluid and the dispersive contribution to the Helmholtz free energy is fitted to the series of $n$-alkanes [16].

VLE calculations using the BIPs fitted to the literature data present substantial improvement, decreasing, on average, by around $65 \%$ the deviation on bubble point pressures and $40 \%$ on the vapour-phase composition. In order to continue comparing the equations of state, the BIPs have been used for studying statistically the results of the four models. 
The average $k_{i j}$ 's for the four EoSs have been calculated by averaging the regressed BIPs for all the binary systems. The CEoS present similar average $k_{i j}$ around 0.068 , while the SAFTlike EoSs give smaller values, 0.045 for the PC-SAFT EoS and 0.031 for the SAFT-VR Mie EoS. The average $k_{i j}$ can be an indicator of the predictive capability of the model for multicomponent systems. A small average $k_{i j}$ implies that a smaller adjustment is necessary to tune it from the default state $\left(k_{i j}=0\right)$ to the optimal value [19].

A sensitivity analysis has been performed in order to understanding how much the \%AAD decreases by the employment of the optimal $k_{i j}$. The sensitivities between predicted (predic) and calculated ( $\mathrm{calc}$ ) bubble pressures and vapour compositions are calculated as

Sensitivity $\Delta P^{\text {bubble }}=\frac{1}{N} \sum_{i=1}^{N}\left|\left(\Delta P_{\text {calc }}-\Delta P_{\text {predic }}\right) / k_{i j}\right|$

Sensitivity $\Delta y_{1}=\frac{1}{N} \sum_{i=1}^{N}\left|\left(\Delta y_{\text {calc }}-\Delta y_{\text {predic }}\right) / k_{i j}\right|$

The average sensitivities for the $\Delta P$ and $\Delta y_{1}$, as well as the average $k_{i j}$, are reported in Table 8 . As it can be observed in this table, two levels of sensitivity can be differentiated between the CEoS and the SAFT-based EoS, being PC-SAFT and SAFT-VR Mie EoS twice more sensitive than PR and SRK models. For example, according to the average sensitivity, by modifying 0.1 the value of the $k_{i j}$, it changes the deviation on bubble point pressure in $1.4 \%$ for the CEoS, $2.7 \%$ for the PC-SAFT EoS and $2.9 \%$ for the SAFT-VR Mie EoS. It also important to note that there is no linear change between $\Delta P$ and $k_{i j}$, but in this work the sensitivity index is roughly well defined by our calculated average sensitivities [19].

\subsection{Density calculations}

The capability of the models to describe pure compound densities is first compared. 22 components have been selected from the 27 compounds that are presented in this work, dismissing the long-chain alkanes (longer than $n \mathrm{C}_{12}$ ) due to the unavailability of correlations of data for these compounds in the whole ranges of pressure and temperature. The pure compound density comparison is divided into saturated-liquid density and single-phase fluid density predictions $(P T \rho)$ at gas, liquid and supercritical (SC) states.

First, the saturated-liquid density of the studied compounds has been correlated by SRK, PR, PC-SAFT and SAFT-VR Mie EoS at 15 temperatures below $0.9 T_{r}$. The deviations in the calculated liquid saturated densities are shown in Figure 8. On average, the SAFT-VR Mie 
EoS leads to AAD below $1 \%$, slightly smaller than $1.4 \%$ for the PC-SAFT model and significantly smaller than the AAD of the CEoS, $6 \%$ for PR and $12 \%$ for SRK. The PR EoS better predicts the saturated-liquid density of $\mathrm{CO}_{2}$, most alkanes and aromatic compounds than the SRK EoS, while the SRK EoS is more accurate for small molecules like $\mathrm{CH}_{4}, \mathrm{~N}_{2}, \mathrm{O}_{2}$, $\mathrm{Ar}$ and $\mathrm{CO}$. The saturated density predictions of the CEoS are improved using the Peneloux volume correction, decreasing the $\mathrm{AAD} \%$ to $4 \%$ for the $\mathrm{PR}+\mathrm{VC}$ and $6 \%$ for the $\mathrm{SRK}+\mathrm{VC}$.

The SAFT-based models require the use of experimental vapour pressures, saturated-liquid densities and $P T \rho$ data to fit the molecular parameters, therefore it was evident that the SAFTbased EoS predict saturated-liquid density better than the CEoS. Obviously, the SAFT-VR Mie EoS with 5 molecular parameters correlates the saturated properties with lower deviations than PC-SAFT with 3 parameters. However, unlike the cubic models, the SAFT models do not reproduce well the critical point $(\mathrm{CP})$, especially the critical pressure $\left(\mathrm{P}_{\mathrm{c}}\right)$, and this leads to larger density deviations around the CP. Again, the SAFT-VR Mie EoS predicts comparatively better the critical point than the PC-SAFT model. An example of CP calculations is reported in Table 9 for $\mathrm{CO}_{2}$. It can be observed that, as it is usual for SAFTEoS, all the critical properties are overestimated by the PC-SAFT and SAFT-VR Mie EoS.

For the single-phase densities $(P T \rho), 31928$ densities of pure compounds have been obtained from reliable correlations and multi-component EoSs [36]. Thus, the PT $\rho$ data of the 22 components have been evaluated at 15 temperatures between 253 and $523 \mathrm{~K}$ and pressures up to $150 \mathrm{MPa}$, at gas, liquid or SC states depending on $P-T$ conditions. The deviations of the density calculations are presented as \%AAD, as well as the maximum average deviation (MAD\%), i.e. the largest value in a set of absolute deviations. As mentioned in section 2, the use of volume corrections can improve density calculations of fluid dense phases.

In Table 10, the results of PT $\rho$ modelling with PC-SAFT, SAFT-VR Mie and the cubic EoSs with and without volume correction (VC) are reported. In general, the deviations are similar to the results of the correlated saturated-liquid densities; the SAFT-VR Mie EoS is the most accurate model for the predictions of $P T \rho$ (1.2\% AAD), followed by the PC-SAFT (1.6\% AAD), PR (6.7\% AAD) and SRK (7.4\% AAD) EoSs. By comparing the two cubic EoSs, it can be observed that the SRK EoS better predicts the densities of gas molecules and shortchain alkanes (until $n$-butane). However, the PR EoS provides better predictions for aromatics and longer alkanes. It can be seen a considerable improvement when cubic models are combined with the Peneloux volume translation, as expected, and deviations to experimental densities are reduced by more than $70 \%$. The SRK+Peneloux and PR+Peneloux deviations 
are around $2 \%$ and these results are actually comparable to the deviations reported for SAFTlike EoS. However, it is worth mentioning that the maximum absolute deviation (\%MAD) for the CEoS are much higher than the \%MAD reported for the PC-SAFT and SAFT-VR Mie EoSs and, despite the use of the volume correction, gives better average results, in many cases the \%MAD is slightly higher when applying the Peneloux-VC.

The second stage of the density calculations analysis is the modelling of binary systems. The experimental density data available for the studied mixtures are summarised in Table 1 and, as it can be seen, there are no data for many of the considered systems during the VLE analysis. Therefore, 26479 single phase density $(P T \rho x)$ literature data were collected from NIST standard reference database [37], even though it is worth noting that the data used for the mixture with long-chain alkanes are saturated liquid density data points. The density data of 57 binary mixtures of $\mathrm{CO}_{2}, \mathrm{CH}_{4}, \mathrm{C}_{2} \mathrm{H}_{6}, \mathrm{~N}_{2}$ and $\mathrm{H}_{2} \mathrm{~S}$ with alkanes, gases and toluene were modelled with the SRK, PR, PC-SAFT and SAFT-VR Mie equation of state, as well as using the Peneloux volume correction coupled with CEoS. The phase equilibria of all these binary systems were studied and are presented in the VLE section. Therefore, the previously reported BIP are used herein in order to avoid the wrong prediction of the two phase region during PT $\rho x$ calculation.

The AAD in density calculations using the investigated EoS are reported in Tables 11-15. The number of data taken into consideration, the ranges of temperatures, pressures and compositions are presented in these tables, besides the average absolute deviations of the different investigated models.

The average absolute deviations in density calculations of binary system are summarised in Figure 9. The models can be divided into three groups according to their level of agreement to the experimental data: SAFT-EoS (2.75\% AAD), CEoS+VC (3.5\% AAD) and CEoS without VC $\left(6.75 \%\right.$ AAD). In Figure 10 and 11, the densities of $\mathrm{C}_{2} \mathrm{H}_{6}+\mathrm{H}_{2} \mathrm{~S}$ and $\mathrm{CO}_{2}+\mathrm{H}_{2} \mathrm{~S}$ systems are performed using one of each group of equations in order to illustrate the usual results comparing the density calculations from SAFT-EoS, CEoS+VC and CEoS. The more precise models are the SAFT-based EoS; the SAFT-VR Mie EoS predicts densities with higher accuracy than the other investigated models for most of the studied systems. Nevertheless, the PC-SAFT model gives better density calculations for mixtures with long-chain alkanes, for example the saturated liquid density of the systems $\mathrm{CO}_{2}+n \mathrm{C}_{20}, \mathrm{CH}_{4}+n \mathrm{C}_{20}$ and $\mathrm{C}_{2} \mathrm{H}_{6}+n \mathrm{C}_{20}$ are described with around 30\% lower AAD than with the SAFT-VR Mie EoS. In a second level of accuracy, the CEoS coupled with the Peneloux volume translation report a little 
higher average deviation than the PC-SAFT model, indeed density calculations of the $\mathrm{N}_{2}+$ Comp2 are better performed using the CEoS+VC than the PC-SAFT EoS (Figure 12). Finally, the CEoS without the Peneloux volume translation present the lowest accuracy in density calculations; the AAD without VC almost doubles the deviations coupling the volume translation. Therefore, as obtained for pure compounds, the density calculations of binary mixtures with CEoS are significantly improved using the VC and both CEoS perform with similar accuracy. On the one hand, the PR EoS is on average slightly more accurate and it better predicts the densities of $\mathrm{C}_{2} \mathrm{H}_{6}$ and $\mathrm{H}_{2} \mathrm{~S}+\mathrm{Comp} 2$ binary systems. On the other hand, the SRK EoS leads to better results for the $\mathrm{CO}_{2}, \mathrm{CH}_{4}$ and $\mathrm{N}_{2}+$ Comp2 mixtures, as shown in Figure 13 for the $\mathrm{CH}_{4}+\mathrm{N}_{2}$ system.

\section{Remarks and Conclusions}

A comprehensible comparison has been made between the SRK, PR, PC-SAFT and SAFTVR Mie EoSs in the scope of CCS. These models were used to describe both VLE and density data. The investigated equations of state have been used to predict the phase behaviour of 108 binary systems of typical components of flue gases and reservoir fluids. In general, the SAFTVR Mie EoS better predicts the VLE with an average deviation of $13.3 \%$ compared to the experimental data for equilibrium pressure, followed by the CEoS, with $13.7 \%$ for the SRK and $14.2 \%$ for the PR EoSs. Independent temperature binary interaction parameters (BIPs) have been regressed on the VLE data. Using fitted BIPs, the SAFT-VR Mie EoS is the most accurate model among the four, to correlate the phase equilibria of the investigated systems, with an AAD of $4.71 \%$, slightly higher deviations are observed for PR (4.73\%) and SRK $(4.82 \%)$. The PC-SAFT EoS is the model which reports on average a little higher deviation $(5.03 \%)$, however it is worth noting that the PC-SAFT model correlates the systems with alkanes better than CEoS. In addition, the SAFT-based EoSs are more sensitive to the variation of $k_{i j}$ than the CEoS. Therefore, SAFT-like EoSs have better predictive capabilities as smaller $k_{i j}$ are necessary. However, there is no big increase in accuracy between the correlations from CEoS and SAFT-EoS when the BIPs are used. Therefore, one may prefer to use a simpler and computationally faster CEoS when the BIPs can be optimized using available VLE data, or the more-complex SAFT-VR Mie EoS when a high predictive capability is required.

Both PC-SAFT and SAFT-VR Mie EoSs are more accurate than the SRK and PR models in density calculations of the 22 selected pure components. First, saturated-liquid densities at temperature below $0.9 \mathrm{~T}_{\mathrm{r}}$ have been performed by the SAFT-VR Mie EoS with an average 
absolute deviation of $0.6 \%$, while the PC-SAFT, PR and SRK models report, respectively, an AAD of $1.4 \%, 6.1 \%$ and $10.2 \%$. Secondly, single-phase densities at 15 temperatures between 253 and $523 \mathrm{~K}$ and pressures up to $150 \mathrm{MPa}$ were correlated by using the investigated models with different levels of agreement. Again, the SAFT-VR Mie EoS is the model that best correlates the $P T \rho$ data with an AAD of $1.2 \%$. In order to improve the poor density predictions from the CEoS, the Peneloux volume translation were used with the SRK and PR models and the deviations in the density calculations were reduced by more than $70 \%$.

Finally, the single-phase fluid densities of 57 binary systems were performed by the evaluated models using the $k_{i j}$ regressed in this work. In this part of the comparative study, the SAFTVR Mie EoS leads to the lowest deviation in modelling the density of most of binary systems. On average, the deviations in the $P T \rho x$ calculations of binary systems are $\mathrm{AAD}=2.75 \%$ for the SAFT-like EoSs, $\mathrm{AAD}=3.5 \%$ for the $\mathrm{CEOS}+\mathrm{VC}$ and $\mathrm{AAD}=6.75 \%$ for the $\mathrm{CEoS}$ without VC.

In summary, the VLE and densities of the investigated systems were predicted with higher accuracy using the SAFT-VR Mie EoS, as it was expected. This is because of the higher complexity and flexibility (two extra parameters) of the model in comparison with CEoS and PC-SAFT. Although the computational time has not been evaluated quantitatively, it is remarkable to note that modelling with the SAFT-VR Mie model requires much longer computational time than the CEoS. Despite the differences between the SRK, PR, PC-SAFT and SAFT-VR Mie equations of state, it can be concluded that the investigated models are accurate enough for PVT modelling of fluids related to carbon capture. The comparison may be completed by further studies with associative compounds (i.e. water) also related to CCS, other associating models (for example CPA) and more thermophysical properties $\left(c_{p}\right.$, speed of sound or IFT). 
Table 1. Vapour-liquid equilibrium ( $\square$ ) and density ( $\square$ ) data available in the literature for the binary systems studied in this work.

\begin{tabular}{|c|c|c|c|c|c|c|}
\hline & & $\mathrm{CO}_{2}$ & $\mathrm{H}_{2} \mathrm{~S}$ & $\mathrm{~N}_{2}$ & Methane & Ethane \\
\hline 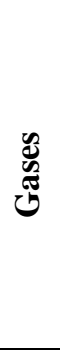 & $\begin{array}{l}\mathrm{CO}_{2} \\
\mathrm{H}_{2} \mathrm{~S} \\
\mathrm{~N}_{2} \\
\mathrm{O}_{2} \\
\mathrm{Ar} \\
\mathrm{SO}_{2} \\
\mathrm{CO} \\
\end{array}$ & $\begin{array}{c}\boldsymbol{\square} \\
\mathbf{\square} \\
\boldsymbol{\square} \square \\
\boldsymbol{\square} \square \\
\mathbf{\square} \\
\mathbf{\square} \\
\end{array}$ & . & 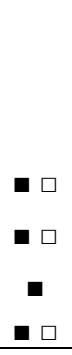 & $\begin{array}{c}\text { घ } \\
\text { घ } \\
\text { घ } \square \\
\end{array}$ & $\begin{array}{c}\square \\
\text { घ } \square \\
\end{array}$ \\
\hline 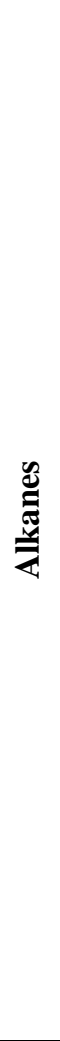 & $\begin{array}{l}\mathrm{C}_{1} \\
\mathrm{C}_{2} \\
\mathrm{C}_{3} \\
\mathrm{iC}_{4} \\
\mathrm{nC}_{4} \\
\mathrm{iC}_{5} \\
\mathrm{nC}_{5} \\
\mathrm{nC}_{6} \\
\mathrm{nC}_{7} \\
\mathrm{nC}_{8} \\
\mathrm{nC}_{9} \\
\mathrm{nC}_{10} \\
\mathrm{nC}_{12} \\
\mathrm{nC}_{14} \\
\mathrm{nC}_{15} \\
\mathrm{nC}_{16} \\
\mathrm{nC}_{18} \\
\mathrm{nC}_{20} \\
\mathrm{nC}_{24} \\
\mathrm{nC}_{32}\end{array}$ & 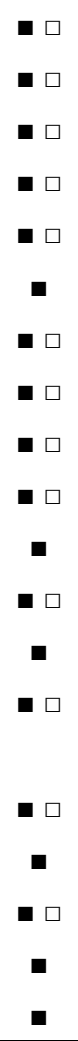 & 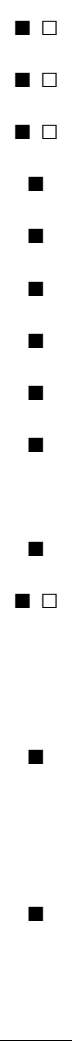 & 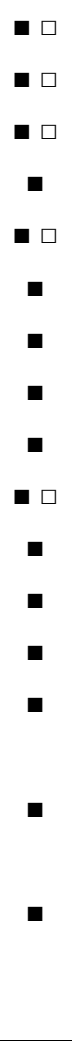 & 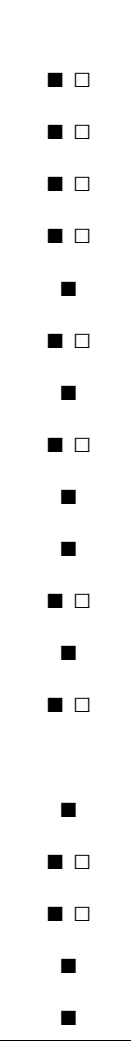 & 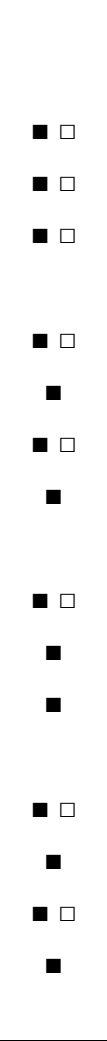 \\
\hline$\dot{\psi}$ & $\begin{array}{l}\text { Benzene } \\
\text { Toluene }\end{array}$ & $\begin{array}{c}\square \\
\square\end{array}$ & $\begin{array}{c}\square \\
\square\end{array}$ & घ & घ & घ \\
\hline
\end{tabular}


Table 2. Average absolute deviations (\%AAD) in predictions $\left(k_{i j}=0\right)$ and calculations (using regressed $k_{i j}$ 's) of bubble pressures $\left(\Delta P^{b u b b l e}\right)$ and vapour phase compositions $\left(\Delta y_{1}\right)$ of $\mathrm{CO}_{2}+\mathrm{Comp2}$ binary systems with the SRK, PR, PC-SAFT and SAFT-VR Mie EoS.

\begin{tabular}{|c|c|c|c|c|c|c|c|c|c|c|c|c|c|}
\hline \multirow{2}{*}{ Comp2 } & \multirow{2}{*}{$\begin{array}{c}\mathrm{T}_{\text {range }} \\
{[\mathrm{K}]}\end{array}$} & \multicolumn{3}{|c|}{ SRK } & \multicolumn{3}{|c|}{ PR } & \multicolumn{3}{|c|}{ PCSAFT } & \multicolumn{3}{|c|}{ SAFT-VR Mie } \\
\hline & & $\mathrm{k}_{\mathrm{ij}}$ & $\Delta \mathrm{P}$ & $\Delta \mathrm{y}_{1}$ & $\mathrm{k}_{\mathrm{ij}}$ & $\Delta \mathrm{P}$ & $\Delta \mathrm{y}_{1}$ & $\mathrm{k}_{\mathrm{ij}}$ & $\Delta \mathrm{P}$ & $\Delta \mathrm{y}_{1}$ & $\mathrm{k}_{\mathrm{ij}}$ & $\Delta \mathrm{P}$ & $\Delta \mathrm{y}_{1}$ \\
\hline \multirow{2}{*}{$\mathrm{CH}_{4}$} & 143 & 0 & 13.49 & 3.88 & 0 & 13.35 & 3.99 & 0 & 10.22 & 3.26 & 0 & 2.76 & 3.01 \\
\hline & 301 & 0.0956 & 2.83 & 2.12 & 0.0951 & 2.41 & 1.83 & 0.0856 & 3.82 & 2.41 & 0.0042 & 2.28 & 2.82 \\
\hline \multirow{2}{*}{$\mathrm{C}_{2}$} & 207 & 0 & 15.39 & 6.42 & 0 & 15.76 & 6.36 & 0 & 14.61 & 6.88 & 0 & 13.22 & 7.56 \\
\hline & 298 & 0.1359 & 3.24 & 2.19 & 0.1278 & 3.19 & 2.27 & 0.0650 & 2.93 & 2.74 & 0.0537 & 2.12 & 2.32 \\
\hline \multirow{2}{*}{$\mathrm{C}_{3}$} & 210 & 0 & 15.66 & 6.14 & 0 & 15.44 & 5.98 & 0 & 15.68 & 7.03 & 0 & 15.35 & 6.61 \\
\hline & 366 & 0.1388 & 3.28 & 1.06 & 0.1318 & 3.27 & 1.09 & 0.0724 & 3.07 & 0.61 & 0.0674 & 2.30 & 0.58 \\
\hline \multirow{2}{*}{$\mathrm{nC}_{4}$} & 227 & 0 & 14.76 & 4.66 & 0 & 14.57 & 4.73 & 0 & 14.83 & 6.2 & 0 & 12.62 & 7.03 \\
\hline & 418 & 0.1392 & 3.11 & 1.31 & 0.1351 & 2.95 & 1.33 & 0.0620 & 3.26 & 1.01 & 0.0531 & 1.81 & 0.94 \\
\hline \multirow{2}{*}{$\mathrm{iC}_{4}$} & 250 & 0 & 13.88 & 4.88 & 0 & 13.74 & 4.82 & 0 & 12.79 & 4.63 & 0 & 11.45 & 4.71 \\
\hline & 398 & 0.131 & 3.74 & 1.84 & 0.1256 & 3.48 & 1.91 & 0.0646 & 3.38 & 1.77 & 0.0549 & 3.13 & 1.80 \\
\hline \multirow{2}{*}{$\mathrm{nC}_{5}$} & 252 & 0 & 12.43 & 3.91 & 0 & 12.47 & 3.96 & 0 & 11.74 & 3.40 & 0 & 10.86 & 3.71 \\
\hline & 463 & 0.1292 & 5.05 & 1.95 & 0.1252 & 4.69 & 1.82 & 0.0665 & 4.31 & 1.18 & 0.0556 & 4.02 & 1.22 \\
\hline \multirow{2}{*}{$\mathrm{iC}_{5}$} & 253 & 0 & 16 & 3.78 & 0 & 16.04 & 3.69 & 0 & 14.64 & 3.09 & 0 & 13.95 & 3.14 \\
\hline & 453 & 0.1221 & 3.91 & 1.77 & 0.1158 & 3.63 & 1.78 & 0.0649 & 3.5 & 1.65 & 0.0550 & 3.37 & 1.70 \\
\hline \multirow{2}{*}{$\mathrm{nC}_{6}$} & 238 & 0 & 15.73 & 2.71 & 0 & 15.62 & 2.63 & 0 & 16.95 & 2.97 & 0 & 16.21 & 3.04 \\
\hline & 393 & 0.1294 & 4.61 & 0.99 & 0.1212 & 4.40 & 1.04 & 0.0711 & 3.71 & 0.82 & 0.0669 & 3.88 & 0.92 \\
\hline & 238 & 0 & 17.3 & 3.21 & 0 & 17.44 & 3.08 & 0 & 15.84 & 3.13 & 0 & 15.60 & 3.18 \\
\hline $\mathrm{nC}_{7}$ & 501 & 0.1103 & 5 & 1.70 & 0.1035 & 5.06 & 1.81 & 0.0538 & 5.89 & 1.77 & 0.0483 & 5.26 & 1.57 \\
\hline & 238 & 0 & 15.54 & 1.75 & 0 & 15.50 & 1.72 & 0 & 15.04 & 1.79 & 0 & 14.79 & 1.85 \\
\hline & 531 & 0.1236 & 6.05 & 1.30 & 0.1163 & 6.12 & 1.25 & 0.0704 & 6.26 & 1.25 & 0.0638 & 5.47 & 1.24 \\
\hline & 315 & 0 & 20.05 & 1.11 & 0 & 19.21 & 1.03 & 0 & 17.74 & 1.53 & 0 & 17.42 & 1.46 \\
\hline & 418 & 0.1086 & 2.72 & 0.57 & 0.0958 & 2.58 & 0.50 & 0.0580 & 2.63 & 0.55 & 0.0502 & 2.55 & 0.58 \\
\hline & 277 & 0 & 19.61 & 2.51 & 0 & 18.95 & 2.43 & 0 & 16.63 & 3.76 & 0 & 15.92 & 3.13 \\
\hline & 583 & 0.1089 & 4.94 & 0.89 & 0.0987 & 4.15 & 0.83 & 0.0631 & 4.33 & 0.89 & 0.0568 & 2.08 & 1.11 \\
\hline & 313 & 0 & 10.67 & - & 0 & 10.75 & - & 0 & 7.81 & - & 0 & 7.96 & - \\
\hline & 417 & 0.0970 & 1.69 & - & 0.0905 & 1.27 & - & 0.0662 & 0.89 & - & 0.0594 & 1.03 & - \\
\hline & 290 & 0 & 12.9 & - & 0 & 14.32 & - & 0 & 14.96 & - & 0 & 15.45 & - \\
\hline & 373 & 0.0993 & 1.78 & - & 0.0944 & 1.59 & - & 0.0697 & 3.34 & - & 0.0633 & 3.42 & - \\
\hline & 283 & 0 & 16.52 & - & 0 & 15.87 & - & 0 & 16.50 & - & 0 & 17.76 & - \\
\hline & & 0.1016 & 4.35 & - & 0.0989 & 4.46 & - & 0.0605 & 5.21 & - & 0.0588 & 5.40 & - \\
\hline & 323 & 0 & 16.73 & - & 0 & 14.57 & - & 0 & 17.10 & - & 0 & 19.43 & - \\
\hline & & 0.0859 & 7.31 & - & 0.0683 & 7.72 & - & 0.0589 & 7.36 & - & 0.0419 & 7.55 & - \\
\hline & 300 & 0 & 20.9 & - & 0 & 21.19 & - & 0 & 16.33 & - & 0 & 22.19 & - \\
\hline & & 0.0987 & 5.77 & - & 0.0908 & 5.86 & - & 0.0640 & 4.17 & - & 0.0504 & 5.27 & - \\
\hline & & 0 & 11.21 & - & 0 & 9.88 & - & 0 & 15.82 & - & 0 & 18.78 & - \\
\hline & & 0.0622 & 5.36 & - & 0.0560 & 6.20 & - & 0.0596 & 5.06 & - & 0.0244 & 6.60 & - \\
\hline & & 0 & 10.37 & - & 0 & 11.92 & - & 0 & 19.60 & - & 0 & 10.93 & - \\
\hline & & 0.0198 & 5.79 & - & 0.0161 & 6.04 & - & 0.0427 & 5.14 & - & 0.0248 & 5.37 & - \\
\hline & 224 & 0 & 12.31 & 4.91 & 0 & 12.95 & 4.96 & 0 & 14.13 & 5.36 & 0 & 13.86 & 5.23 \\
\hline & 366 & 0.0984 & 1.46 & 1.09 & 0.0966 & 1.44 & 1.46 & 0.0618 & 1.68 & 0.95 & 0.0621 & 1.12 & 1.89 \\
\hline & 218 & 0 & 5.50 & 3.56 & 0 & 3.86 & 2.92 & 0 & 6.02 & 2.27 & 0 & 22.35 & 8.28 \\
\hline $\mathbf{N}_{2}$ & 301 & -0.0245 & 2.88 & 3.63 & -0.0192 & 3.05 & 3.10 & -0.0079 & 4.89 & 1.91 & -0.1083 & 6.31 & 2.85 \\
\hline & 218 & 0 & 21.78 & 11.09 & 0 & 22.82 & 12.11 & 0 & 20.80 & 11.09 & 0 & 19.21 & 10.02 \\
\hline $\mathrm{U}_{2}$ & & 0.1072 & 5.54 & 4.04 & 0.1188 & 6.31 & 3.69 & 0.0475 & 7.63 & 6.47 & -0.0291 & 5.01 & 3.68 \\
\hline & 233 & 0 & 23.03 & 7.85 & 0 & 17.53 & 7.88 & 0 & 15.80 & 8.06 & 0 & 14.17 & 8.12 \\
\hline Ar & 299 & 0.123 & 5.82 & 4.31 & 0.1211 & 6.86 & 2.93 & 0.0213 & 5.51 & 3.96 & -0.0163 & 6.25 & 2.66 \\
\hline & 313 & 0 & 11.98 & - & 0 & 12.88 & - & 0 & 17.00 & - & 0 & 6.19 & - \\
\hline & 403 & 0.0676 & 5.46 & - & 0.0671 & 5.55 & - & 0.0424 & 7.85 & - & 0.0078 & 4.83 & - \\
\hline & 223 & 0 & 12.29 & 3.91 & 0 & 10.28 & 2.83 & 0 & 9.65 & 5.59 & 0 & 8.03 & 4.95 \\
\hline $\mathrm{CO}$ & 283 & -0.0710 & 5.50 & 5.05 & -0.0573 & 5.70 & 4.38 & -0.0103 & 6.89 & 4.85 & -0.0078 & 6.18 & 5.49 \\
\hline & 273 & 0 & 20.25 & 1.77 & 0 & 21.50 & 1.85 & 0 & 27.82 & 3.75 & 0 & 21.66 & 1.80 \\
\hline Benzene & 413 & 0.0987 & 7.07 & 1.20 & 0.0992 & 6.23 & 1.24 & 0.0433 & 8.91 & 6.04 & 0.0776 & 7.08 & 1.87 \\
\hline & 230 & 0 & 27.27 & 6.54 & 0 & 28.49 & 6.57 & 0 & 45.99 & 9.85 & 0 & 19.70 & 6.31 \\
\hline & 572 & 0.1012 & 6.56 & 6.00 & 0.0995 & 6.40 & 5.84 & 0.0965 & 13.87 & 7.13 & 0.0481 & 10.45 & 5.55 \\
\hline
\end{tabular}


Table 3. Average absolute deviations (\%AAD) in predictions $\left(k_{i j}=0\right)$ and calculations (using regressed $k_{i j}$ 's) of bubble pressures $\left(\Delta P^{b u b b l e}\right)$ and vapour phase compositions $\left(\Delta y_{1}\right)$ of $\mathrm{CH}_{4}+\mathrm{Comp2}$ binary systems with the SRK, PR, PC-SAFT and SAFT-VR Mie EoS.

\begin{tabular}{|c|c|c|c|c|c|c|c|c|c|c|c|c|c|}
\hline \multirow{2}{*}{ Comp2 } & \multirow{2}{*}{$\begin{array}{c}\mathrm{T}_{\text {range }} \\
{[\mathrm{K}]}\end{array}$} & \multicolumn{3}{|c|}{ SRK } & \multicolumn{3}{|c|}{ PR } & \multicolumn{3}{|c|}{ PCSAFT } & \multicolumn{3}{|c|}{ SAFT-VR Mie } \\
\hline & & $\mathrm{k}_{\mathrm{ij}}$ & $\Delta \mathrm{P}$ & $\Delta \mathrm{y}_{1}$ & $\mathrm{k}_{\mathrm{ij}}$ & $\Delta \mathrm{P}$ & $\Delta \mathrm{y}_{1}$ & $\mathrm{k}_{\mathrm{ij}}$ & $\Delta \mathrm{P}$ & $\Delta \mathrm{y}_{1}$ & $\mathrm{k}_{\mathrm{ij}}$ & $\Delta \mathrm{P}$ & $\Delta \mathrm{y}_{1}$ \\
\hline \multirow{2}{*}{$\mathrm{CO}_{2}$} & 143 & 0 & 13.45 & 3.85 & 0 & 13.40 & 4.00 & 0 & 10.13 & 3.25 & 0 & 2.72 & 2.99 \\
\hline & & 0.0956 & 2.78 & 2.10 & 0.0951 & 2.56 & 1.84 & 0.0356 & 3.42 & 2.39 & 0.0042 & 2.24 & 2.79 \\
\hline \multirow{2}{*}{$\mathrm{C}_{2}$} & 130 & 0 & 1.76 & 1.26 & 0 & 1.73 & 1.20 & 0 & 6.04 & 3.79 & 0 & 3.58 & 1.99 \\
\hline & 283 & -0.0029 & 1.72 & 1.24 & 0.0012 & 1.67 & 1.17 & 0.0131 & 3.18 & 3.33 & 0.0007 & 3.36 & 1.94 \\
\hline \multirow{2}{*}{$\mathrm{C}_{3}$} & 90 & 0 & 4.95 & 1.64 & 0 & 5.51 & 1.80 & 0 & 3.63 & 0.89 & 0 & 3.84 & 0.97 \\
\hline & 360 & 0.0088 & 3.61 & 1.51 & 0.0149 & 2.53 & 1.52 & 0.0117 & 2.01 & 0.99 & -0.0028 & 3.50 & 0.96 \\
\hline \multirow{2}{*}{$\mathrm{nC}_{4}$} & 144 & 0 & 5.18 & 0.97 & 0 & 6.57 & 0.94 & 0 & 5.62 & 0.90 & 0 & 5.27 & 0.51 \\
\hline & 411 & 0.0111 & 4.41 & 0.85 & 0.0190 & 4.24 & 0.75 & -0.0044 & 5.06 & 0.87 & -0.0063 & 4.72 & 0.55 \\
\hline \multirow{2}{*}{$\mathrm{iC}_{4}$} & & 0 & 6.39 & 2.11 & 0 & 6.42 & 2.16 & 0 & 5.66 & 1.77 & 0 & 5.19 & 1.85 \\
\hline & 377 & 0.0239 & 3.20 & 1.78 & 0.0250 & 3.33 & 1.86 & 0.0194 & 2.84 & 1.82 & 0.0094 & 3.17 & 1.74 \\
\hline \multirow{2}{*}{$\mathrm{nC}_{5}$} & & 0 & 5.21 & 2.25 & 0 & 6.86 & 2.43 & 0 & 7.77 & 2.46 & 0 & 5.91 & 1.33 \\
\hline & 9 & 0.0171 & 2.35 & 1.97 & 0.0241 & 2.24 & 1.62 & 0.0099 & 5.32 & 1.96 & -0.0116 & 4.41 & 1.13 \\
\hline \multirow{2}{*}{$\mathrm{iC}_{5}$} & 44 & 0 & 6.43 & 6.77 & 0 & 6.80 & 7.14 & 0 & 6.55 & 6.69 & 0 & 6.05 & 6.32 \\
\hline & 0 & -0.0078 & 5.39 & 6.65 & -0.0056 & 6.30 & 7.01 & 0.0089 & 5.22 & 6.57 & 0.0058 & 5.37 & 6.20 \\
\hline \multirow{2}{*}{$\mathrm{nC}_{6}$} & & 0 & 11.42 & 0.89 & 0 & 13.69 & 0.80 & 0 & 12.46 & 0.58 & 0 & 10.83 & 0.65 \\
\hline & & 0.0233 & 5.43 & 0.82 & 0.0302 & 5.33 & 0.71 & 0.0121 & 6.52 & 0.47 & 0.0095 & 5.39 & 0.52 \\
\hline \multirow{2}{*}{$\mathrm{nC}_{7}$} & 18 & 0 & 11.45 & 1.24 & 0 & 12.02 & 1.17 & 0 & 9.49 & 1.08 & 0 & 8.59 & 0.65 \\
\hline & & 0.0303 & 7.58 & 0.68 & 0.0371 & 7.65 & 0.64 & 0.0184 & 5.61 & 0.81 & -0.0068 & 5.20 & 0.71 \\
\hline & & 0 & 13.68 & 0.79 & 0 & 14.45 & 0.79 & 0 & 11.87 & 0.74 & 0 & 10.63 & 0.74 \\
\hline $\mathrm{nC}_{8}$ & & 0.0441 & 4.09 & 0.47 & 0.0489 & 4.26 & 0.47 & 0.0143 & 4.827 & 0.41 & 0.0086 & 4.69 & 0.42 \\
\hline & 23 & 0 & 14.57 & 0.44 & 0 & 16.82 & 0.45 & 0 & 12.34 & 0.43 & 0 & 9.69 & 0.45 \\
\hline & & 0.0421 & 3.14 & 0.34 & 0.046 & 3.26 & 0.35 & 0.0141 & 4.017 & 0.29 & 0.0083 & 3.92 & 0.30 \\
\hline & 244 & 0 & 8.64 & 1.11 & 0 & 9.44 & 0.97 & 0 & 8.84 & 1.04 & 0 & 8.52 & 0.86 \\
\hline & & 0.0358 & 4.42 & 1.03 & 0.0406 & 4.25 & 0.94 & 0.0186 & 3.927 & 0.85 & -0.0284 & 3.90 & 0.89 \\
\hline & & 0 & 15.05 & - & 0 & 15.59 & - & 0 & 10.19 & - & 0 & 9.12 & - \\
\hline & & 0.0223 & 7.09 & - & 0.0255 & 6.94 & - & 0.0208 & 5.467 & - & -0.0303 & 5.09 & - \\
\hline & & 0 & 15.48 & - & 0 & 15.72 & - & 0 & 13.717 & - & 0 & 15.15 & - \\
\hline & & 0.0312 & 3.47 & - & 0.0333 & 3.45 & - & 0.0223 & 4.027 & - & -0.0340 & 5.44 & - \\
\hline & & 0 & 14.65 & - & 0 & 14.99 & - & 0 & 14.367 & - & 0 & 16.28 & - \\
\hline & & 0.0423 & 5.81 & - & 0.0487 & 5.77 & - & 0.0195 & 4.237 & - & -0.0414 & 5.80 & - \\
\hline & & 0 & 6.97 & - & 0 & 7.14 & - & 0 & 7.737 & - & 0 & 8.13 & - \\
\hline & & -0.0076 & 5.64 & - & -0.0088 & 5.69 & - & 0.0196 & 4.157 & - & -0.0341 & 4.92 & - \\
\hline & & 0 & 14.45 & - & 0 & 14.61 & - & 0 & 11.27 & - & 0 & 18.37 & - \\
\hline & & -0.0281 & 7.40 & - & -0.0303 & 7.16 & - & 0.0180 & 4.777 & - & -0.0373 & 5.46 & - \\
\hline & & 0 & 27.65 & - & 0 & 27.69 & - & 0 & 27.01 & - & 0 & 29.39 & - \\
\hline & & 0.0612 & 9.86 & - & 0.0593 & 10.47 & - & 0.0369 & 5.20 & - & -0.0613 & 8.14 & - \\
\hline & & 0 & 6.89 & - & 0 & 6.59 & - & 0 & 8.57 & - & 0 & 19.944 & - \\
\hline & & -0.0290 & 2.91 & - & -0.0318 & 2.78 & - & 0.0255 & 2.69 & - & -0.0509 & 2.694 & - \\
\hline & 188 & 0 & 15.39 & 5.86 & 0 & 15.98 & 5.96 & 0 & 14.02 & 4.94 & 0 & 13.67 & 5.41 \\
\hline & & 0.0769 & 4.96 & 2.34 & 0.0841 & 4.82 & 2.30 & 0.0386 & 4.63 & 2.08 & 0.0314 & 4.83 & 2.28 \\
\hline & 100 & 0 & 8.19 & 1.85 & 0 & 8.44 & 1.82 & 0 & 8.48 & 1.92 & 0 & 10.604 & 3.17 \\
\hline $\mathrm{N}_{2}$ & & 0.0293 & 2.56 & 1.42 & 0.0305 & 2.38 & 1.17 & 0.0263 & 2.16 & 1.25 & 0.0457 & 3.57 & 2.53 \\
\hline & & 0 & 6.08 & 8.74 & 0 & 5.69 & 8.48 & 0 & 8.04 & 9.14 & 0 & 4.68 & 8.85 \\
\hline Ar & & 0.0277 & 2.32 & 5.36 & 0.0268 & 2.60 & 4.49 & 0.0263 & 5.92 & 6.71 & -0.0063 & 3.27 & 5.90 \\
\hline & & 0 & 50.82 & 7.12 & 0 & 54.89 & 8.46 & 0 & 30.45 & 6.13 & 0 & 5.82 & 1.95 \\
\hline & & 0.1282 & 5.74 & 0.77 & 0.1366 & 5.16 & 0.79 & 0.0586 & 8.65 & 3.21 & 0.0026 & 5.29 & 1.73 \\
\hline & & 0 & 5.71 & 3.82 & 0 & 6.08 & 4.19 & 0 & 9.23 & 4.54 & 0 & 5.49 & 6.34 \\
\hline & & 0.0211 & 2.35 & 3.76 & 0.0232 & 2.33 & 3.44 & 0.0318 & 3.86 & 4.25 & 0.0083 & 3.09 & 4.41 \\
\hline & 270 & 0 & 9.34 & 4.45 & 0 & 12.95 & 4.14 & 0 & 14.57 & 2.99 & 0 & 9.09 & 3.09 \\
\hline & 501 & 0.0284 & 5.35 & 4.15 & 0.0409 & 5.37 & 3.67 & 0.0160 & 8.50 & 3.10 & -0.0249 & 5.00 & 3.33 \\
\hline & 233 & 0 & 21.62 & 5.18 & 0 & 25.16 & 5.28 & 0 & 17.57 & 5.63 & 0 & 21.41 & 1.72 \\
\hline & 543 & 0.0511 & 8.84 & 4.61 & 0.0590 & 9.65 & 4.37 & 0.0344 & 8.45 & 4.19 & -0.0435 & 8.82 & 2.61 \\
\hline
\end{tabular}


Table 4. Average absolute deviations (\%AAD) in predictions $\left(k_{i j}=0\right)$ and calculations (using regressed $k_{i j}$ 's) of bubble pressures $\left(\Delta P^{b u b b l e}\right)$ and vapour phase compositions $\left(\Delta y_{1}\right)$ of $\mathrm{C}_{2} \mathrm{H}_{6}+\mathrm{Comp2}$ binary systems with the SRK, PR, PC-SAFT and SAFT-VR Mie EoS.

\begin{tabular}{|c|c|c|c|c|c|c|c|c|c|c|c|c|c|}
\hline \multirow{2}{*}{ Comp2 } & \multirow{2}{*}{$\begin{array}{c}\mathrm{T}_{\text {range }} \\
{[\mathrm{K}]}\end{array}$} & \multicolumn{3}{|c|}{ SRK } & \multicolumn{3}{|c|}{ PR } & \multicolumn{3}{|c|}{ PCSAFT } & \multicolumn{3}{|c|}{ SAFT-VR Mie } \\
\hline & & $\mathrm{k}_{\mathrm{ij}}$ & $\Delta \mathrm{P}$ & $\Delta \mathrm{y}_{1}$ & $\mathrm{k}_{\mathrm{ij}}$ & $\Delta \mathrm{P}$ & $\Delta \mathrm{y}_{1}$ & $\mathrm{k}_{\mathrm{ij}}$ & $\Delta \mathrm{P}$ & $\Delta \mathrm{y}_{1}$ & $\mathrm{k}_{\mathrm{ij}}$ & $\Delta \mathrm{P}$ & $\Delta \mathrm{y}_{1}$ \\
\hline \multirow{2}{*}{$\mathrm{CO}_{2}$} & 207 & 0 & 15.31 & 6.39 & 0 & 15.75 & 6.35 & 0 & 14.61 & 6.88 & 0 & 13.22 & 7.56 \\
\hline & 298 & 0.1359 & 3.16 & 2.16 & 0.1278 & 3.18 & 2.26 & 0.0650 & 2.93 & 2.74 & 0.0537 & 2.12 & 2.32 \\
\hline \multirow{2}{*}{$\mathrm{C}_{1}$} & 130 & 0 & 1.73 & 1.26 & 0 & 1.67 & 1.17 & 0 & 6.13 & 3.81 & 0 & 3.62 & 2.01 \\
\hline & 283 & -0.0029 & 1.69 & 1.24 & 0.0012 & 1.54 & 1.14 & 0.0121 & 3.28 & 3.35 & 0.0007 & 3.40 & 1.96 \\
\hline \multirow{2}{*}{$\mathrm{C}_{3}$} & 127 & 0 & 4.09 & 2.64 & 0 & 2.65 & 2.76 & 0 & 3.34 & 3.01 & 0 & 2.64 & 2.71 \\
\hline & & -0.0059 & 2.65 & 2.80 & -0.0055 & 2.52 & 2.78 & -0.0046 & 3.04 & 2.76 & -0.0018 & 2.50 & 2.72 \\
\hline \multirow{2}{*}{$\mathrm{nC}_{4}$} & & 0 & 8.29 & 1.96 & 0 & 3.39 & 1.97 & 0 & 3.63 & 1.96 & 0 & 3.33 & 3.07 \\
\hline & 410 & 0.0077 & 4.22 & 2.06 & 0.0079 & 2.94 & 2.18 & -0.0064 & 3.27 & 1.98 & -0.0049 & 2.98 & 2.76 \\
\hline \multirow{2}{*}{$\mathrm{iC}_{4}$} & 203 & 0 & 3.61 & 5.62 & 0 & 2.87 & 5.59 & 0 & 2.37 & 3.23 & 0 & 2.71 & 3.03 \\
\hline & 394 & -0.0079 & 2.95 & 5.00 & -0.0065 & 2.32 & 5.27 & -0.0010 & 2.19 & 3.16 & -0.0038 & 3.02 & 3.13 \\
\hline \multirow{2}{*}{$\mathrm{nC}_{5}$} & 278 & 0 & 2.70 & 2.79 & 0 & 3.00 & 2.63 & 0 & 2.93 & 2.61 & 0 & 2.87 & 2.53 \\
\hline & & 0.0086 & 2.24 & 2.52 & 0.0094 & 2.16 & 2.38 & -0.0049 & 2.18 & 1.93 & -0.0036 & 2.10 & 1.88 \\
\hline \multirow{2}{*}{$\mathrm{nC}_{6}$} & 298 & 0 & 6.40 & 3.35 & 0 & 6.31 & 3.33 & 0 & 7.47 & 3.85 & 0 & 9.74 & 3.43 \\
\hline & & -0.0091 & 5.65 & 3.39 & -0.0062 & 5.55 & 3.37 & -0.0108 & 5.62 & 3.13 & -0.0183 & 5.34 & 2.56 \\
\hline \multirow{2}{*}{$\mathrm{nC}_{7}$} & 235 & 0 & 2.67 & 1.01 & 0 & 2.76 & 1.24 & 0 & 3.18 & 1.11 & 0 & 4.70 & 1.15 \\
\hline & & 0.0058 & 2.69 & 0.99 & 0.0065 & 2.58 & 1.18 & 0.0035 & 2.89 & 0.95 & -0.0158 & 2.55 & 0.74 \\
\hline \multirow{2}{*}{$\mathrm{nC}_{8}$} & 273 & 0 & 4.76 & 0.59 & 0 & 5.40 & 0.56 & 0 & 3.65 & 0.63 & 0 & 2.31 & 0.62 \\
\hline & & -0.0170 & 1.88 & 0.60 & -0.0184 & 1.78 & 0.59 & -0.0041 & 2.84 & 0.60 & -0.0016 & 1.92 & 0.62 \\
\hline \multirow{2}{*}{$\mathrm{nC}_{10}$} & 277 & 0 & 3.96 & 0.96 & 0 & 3.88 & 1.11 & 0 & 9.61 & 1.90 & 0 & 8.17 & 1.14 \\
\hline & & 0.0159 & 3.36 & 0.92 & 0.0143 & 3.27 & 1.08 & 0.0213 & 3.32 & 1.01 & -0.0134 & 3.16 & 0.92 \\
\hline \multirow{2}{*}{$\mathrm{nC}_{12}$} & 298 & 0 & 4.41 & - & 0 & 4.50 & - & 0 & 17.26 & - & 0 & 19.67 & - \\
\hline & & 0.0058 & 3.87 & - & 0.0059 & 3.91 & - & 0.0176 & 3.90 & - & -0.0228 & 3.74 & - \\
\hline \multirow{2}{*}{$\mathrm{nC}_{14}$} & 323 & 0 & 2.29 & - & 0 & 2.14 & - & 0 & 15.20 & - & 0 & 13.33 & - \\
\hline & & 0.0044 & 1.98 & - & 0.0025 & 1.99 & - & 0.0228 & 2.31 & - & -0.0182 & 1.89 & - \\
\hline \multirow{2}{*}{$\mathrm{nC}_{16}$} & & 0 & 5.76 & - & 0 & 7.77 & - & 0 & 18.65 & - & 0 & 20.66 & - \\
\hline & & 0.0059 & 5.50 & - & 0.0049 & 7.35 & - & 0.0194 & 5.47 & - & -0.0275 & 5.28 & - \\
\hline & & 0 & 4.43 & - & 0 & 4.97 & - & 0 & 16.84 & - & 0 & 35.94 & - \\
\hline $\mathrm{nC}_{18}$ & & 0.0010 & 4.40 & - & 0.0052 & 4.63 & - & 0.0243 & 3.29 & - & -0.0361 & 3.39 & - \\
\hline & & 0 & 9.11 & - & 0 & 10.16 & - & 0 & 13.36 & - & 0 & 36.15 & - \\
\hline & & -0.0164 & 7.87 & - & -0.0200 & 7.90 & - & 0.0137 & 5.42 & - & -0.0478 & 3.29 & - \\
\hline & & 0 & 12.76 & - & 0 & 13.21 & - & 0 & 11.69 & - & 0 & 29.63 & - \\
\hline & & -0.0313 & 5.75 & - & -0.0337 & 5.73 & - & -0.0068 & 7.26 & - & -0.0626 & 8.86 & - \\
\hline & & 0 & 14.67 & 5.90 & 0 & 14.72 & 6.13 & 0 & 14.50 & 5.92 & 0 & 13.97 & 4.78 \\
\hline & & 0.0871 & 4.73 & 3.27 & 0.0838 & 4.76 & 3.23 & 0.0645 & 4.49 & 3.67 & 0.0506 & 4.72 & 3.84 \\
\hline & 110 & 0 & 7.08 & 11.20 & 0 & 8.71 & 11.74 & 0 & 8.48 & 9.78 & 0 & 3.29 & 9.45 \\
\hline $\mathrm{N}_{2}$ & & 0.0345 & 3.10 & 8.17 & 0.0386 & 3.49 & 6.49 & 0.0412 & 3.31 & 6.07 & 0.0086 & 3.15 & 6.95 \\
\hline & 103 & 0 & 23.73 & 44.65 & 0 & 25.41 & 68.07 & 0 & 20.38 & 44.77 & 0 & 16.07 & 37.76 \\
\hline & & 0.0512 & 4.67 & 12.33 & 0.0547 & 4.31 & 27.82 & 0.0304 & 1.99 & 18.63 & 0.0253 & 5.04 & 16.77 \\
\hline & 100 & 0 & 6.82 & 32.54 & 0 & 8.05 & 28.04 & 0 & 13.36 & 36.39 & 0 & 10.61 & 33.52 \\
\hline & & 0.0063 & 6.63 & 31.84 & 0.0178 & 6.44 & 25.17 & 0.0124 & 9.35 & 30.26 & 0.0086 & 6.67 & 26.36 \\
\hline & 273 & 0 & 6.94 & 2.96 & 0 & 8.32 & 2.98 & 0 & 9.78 & 5.15 & 0 & 3.85 & 1.88 \\
\hline & & 0.0423 & 3.60 & 2.59 & 0.0321 & 2.08 & 2.22 & 0.0198 & 2.44 & 2.26 & -0.0011 & 3.84 & 1.87 \\
\hline & 373 & 0 & 7.55 & 3.67 & 0 & 8.35 & 3.46 & 0 & 8.73 & 3.78 & 0 & 8.01 & 2.61 \\
\hline & 473 & 0.0088 & 6.92 & 3.46 & 0.0292 & 7.70 & 2.73 & -0.0007 & 7.33 & 3.31 & -0.0109 & 5.69 & 3.46 \\
\hline
\end{tabular}


Table 5. Average absolute deviations (\%AAD) in predictions $\left(k_{i j}=0\right)$ and calculations (using regressed $k_{i j}$ 's) of bubble pressures $\left(\Delta P^{\text {bubble }}\right)$ and vapour phase compositions $\left(\Delta y_{1}\right)$ of $N_{2}+$ Comp2 binary systems with the SRK, PR, PC-SAFT and SAFT-VR Mie EoS.

\begin{tabular}{|c|c|c|c|c|c|c|c|c|c|c|c|c|c|}
\hline \multirow{2}{*}{ Comp2 } & \multirow{2}{*}{$\begin{array}{c}\mathrm{T}_{\text {range }} \\
{[\mathrm{K}]}\end{array}$} & \multicolumn{3}{|c|}{ SRK } & \multicolumn{3}{|c|}{ PR } & \multicolumn{3}{|c|}{ PCSAFT } & \multicolumn{3}{|c|}{ SAFT-VR Mie } \\
\hline & & $\mathrm{k}_{\mathrm{ij}}$ & $\Delta \mathrm{P}$ & $\Delta \mathrm{y}_{1}$ & $k_{i j}$ & $\Delta \mathrm{P}$ & $\Delta \mathrm{y}_{1}$ & $\mathrm{k}_{\mathrm{ij}}$ & $\Delta \mathrm{P}$ & $\Delta \mathrm{y}_{1}$ & $\mathrm{k}_{\mathrm{ij}}$ & $\Delta \mathrm{P}$ & $\Delta \mathrm{y}_{1}$ \\
\hline \multirow{2}{*}{$\mathrm{CO}_{2}$} & 218 & 0 & 5.47 & 3.56 & 0 & 3.86 & 2.92 & 0 & 6.02 & 2.27 & 0 & 22.26 & 8.28 \\
\hline & 301 & -0.0245 & 2.86 & 3.63 & -0.0192 & 3.05 & 3.10 & -0.0079 & 4.89 & 1.91 & -0.1083 & 6.22 & 2.85 \\
\hline \multirow{2}{*}{$\mathrm{C}_{1}$} & 100 & 0 & 8.16 & 1.85 & 0 & 8.38 & 1.80 & 0 & 8.57 & 1.94 & 0 & 10.55 & 3.19 \\
\hline & 199 & 0.0293 & 2.53 & 1.42 & 0.0305 & 2.32 & 1.15 & 0.0263 & 2.25 & 1.27 & 0.0457 & 3.52 & 2.55 \\
\hline \multirow{2}{*}{$\mathrm{C}_{2}$} & 110 & 0 & 7.08 & 11.20 & 0 & 8.71 & 11.74 & 0 & 8.48 & 9.78 & 0 & 3.21 & 9.45 \\
\hline & 297 & 0.0345 & 3.10 & 8.17 & 0.0386 & 3.49 & 6.49 & 0.0412 & 3.31 & 6.07 & 0.0086 & 3.06 & 6.95 \\
\hline \multirow{2}{*}{$\mathrm{C}_{3}$} & 114 & 0 & 13.61 & 3.62 & 0 & 14.03 & 3.57 & 0 & 13.18 & 3.68 & 0 & 12.29 & 4.12 \\
\hline & 353 & 0.0766 & 7.88 & 1.36 & 0.0790 & 7.76 & 1.29 & 0.0588 & 7.59 & 1.11 & 0.0205 & 7.53 & 2.27 \\
\hline \multirow{2}{*}{$\mathrm{nC}_{4}$} & 239 & 0 & 16.41 & 3.54 & 0 & 16.65 & 3.49 & 0 & 17.26 & 3.28 & 0 & 16.25 & 4.86 \\
\hline & 421 & 0.0858 & 7.05 & 2.98 & 0.0813 & 6.84 & 2.75 & 0.0657 & 7.90 & 2.76 & -0.0093 & 9.40 & 3.10 \\
\hline \multirow{2}{*}{$\mathrm{iC}_{4}$} & 120 & 0 & 17.22 & 3.87 & 0 & 18.76 & 4.08 & 0 & 16.92 & 4.36 & 0 & 10.04 & 6.45 \\
\hline & 394 & 0.0956 & 6.19 & 1.96 & 0.0971 & 6.10 & 1.93 & 0.0696 & 6.09 & 1.89 & 0.0197 & 5.79 & 6.56 \\
\hline \multirow{2}{*}{$\mathrm{nC}_{5}$} & 277 & 0 & 14.85 & 2.51 & 0 & 16.43 & 2.87 & 0 & 18.50 & 3.43 & 0 & 12.62 & 2.90 \\
\hline & 447 & 0.0912 & 5.94 & 1.33 & 0.0964 & 5.92 & 1.26 & 0.0650 & 6.35 & 1.87 & -0.0074 & 6.13 & 1.85 \\
\hline \multirow{2}{*}{$\mathrm{iC}_{5}$} & 277 & 0 & 15.60 & 3.06 & 0 & 17.14 & 3.24 & 0 & 21.09 & 5.88 & 0 & 19.99 & 6.02 \\
\hline & 377 & 0.0944 & 5.76 & 1.94 & 0.0967 & 5.62 & 1.91 & 0.0706 & 5.58 & 2.06 & 0.0132 & 7.85 & 2.17 \\
\hline \multirow{2}{*}{$\mathrm{nC}_{6}$} & 233 & 0 & 23.50 & 1.54 & 0 & 26.36 & 1.34 & 0 & 28.60 & 2.24 & 0 & 8.21 & 1.93 \\
\hline & 498 & 0.118 & 8.36 & 1.73 & 0.1295 & 7.21 & 1.35 & 0.0894 & 6.83 & 1.58 & -0.0125 & 5.34 & 1.00 \\
\hline \multirow{2}{*}{$\mathrm{nC}_{7}$} & 251 & 0 & 25.22 & 4.86 & 0 & 25.80 & 5.33 & 0 & 22.69 & 5.98 & 0 & 11.65 & 5.13 \\
\hline & 523 & 0.1311 & 8.47 & 2.71 & 0.1356 & 7.92 & 2.59 & 0.0841 & 6.89 & 2.32 & -0.0150 & 6.97 & 2.10 \\
\hline \multirow{2}{*}{$\mathrm{nC}_{8}$} & 233 & 0 & 27.09 & 5.10 & 0 & 27.36 & 5.25 & 0 & 25.63 & 6.18 & 0 & 25.64 & 6.24 \\
\hline & 543 & 0.1893 & 5.37 & 3.74 & 0.1888 & 5.24 & 3.27 & 0.0893 & 5.30 & 4.85 & -0.0186 & 7.46 & 4.61 \\
\hline & 261 & 0 & 23.39 & 4.01 & 0 & 25.63 & 2.82 & 0 & 29.06 & 3.86 & 0 & 7.92 & 4.25 \\
\hline $\mathrm{nC}_{9}$ & 543 & 0.1829 & 7.61 & 5.00 & 0.1854 & 6.07 & 3.76 & 0.1344 & 6.48 & 3.74 & -0.01455 & 4.96 & 4.09 \\
\hline & 263 & 0 & 18.21 & 0.18 & 0 & 21.79 & 0.19 & 0 & 30.15 & 0.22 & 0 & 29.33 & 0.42 \\
\hline $\mathrm{nC}_{10}$ & 563 & 0.1006 & 4.92 & 0.17 & 0.1118 & 4.66 & 0.16 & 0.1034 & 5.78 & 0.26 & -0.0497 & 4.21 & 0.44 \\
\hline & 298 & 0 & 18.68 & - & 0 & 19.20 & - & 0 & 31.05 & - & 0 & 24.99 & - \\
\hline $\mathrm{nC}_{12}$ & 593 & 0.2106 & 5.24 & - & 0.196 & 3.59 & - & 0.1103 & 5.61 & - & -0.0597 & 4.61 & - \\
\hline & 298 & 0 & 36.04 & - & 0 & 38.21 & - & 0 & 41.46 & - & 0 & 13.56 & - \\
\hline $\mathrm{nC}_{14}$ & 434 & 0.2079 & 8.73 & - & 0.1975 & 8.92 & - & 0.1543 & 8.14 & - & -0.0209 & 6.83 & - \\
\hline & 298 & 0 & 38.66 & - & 0 & 39.42 & - & 0 & 41.06 & - & 0 & 30.31 & - \\
\hline & 703 & 0.2056 & 7.20 & - & 0.2002 & 7.45 & - & 0.1382 & 9.13 & - & -0.0835 & 8.07 & - \\
\hline & 323 & 0 & 26.58 & - & 0 & 27.87 & - & 0 & 33.07 & - & 0 & 31.44 & - \\
\hline $\mathrm{nC}_{20}$ & 423 & 0.2226 & 3.99 & - & 0.2051 & 4.53 & - & 0.1634 & 7.64 & - & -0.0967 & 8.32 & - \\
\hline & 200 & 0 & 34.56 & 11.90 & 0 & 37.55 & 14.25 & 0 & 31.72 & 12.18 & 0 & 24.14 & 10.88 \\
\hline $\mathrm{H}_{2} \mathrm{~S}$ & 344 & 0.1565 & 7.85 & 3.22 & 0.1738 & 5.49 & 2.80 & 0.1294 & 5.48 & 3.97 & 0.0708 & 5.28 & 2.97 \\
\hline & 100 & 0 & 4.46 & 2.68 & 0 & 4.21 & 2.20 & 0 & 3.61 & 1.86 & 0 & 3.65 & 3.09 \\
\hline $\mathrm{O}_{2}$ & 136 & -0.0142 & 2.43 & 1.27 & -0.0129 & 2.23 & 0.93 & -0.0122 & 2.91 & 1.10 & 0.0025 & 1.80 & 2.28 \\
\hline & 100 & 0 & 2.53 & 1.10 & 0 & 2.32 & 0.89 & 0 & 1.96 & 1.87 & 0 & 3.56 & 2.86 \\
\hline $\mathrm{Ar}$ & 134 & -0.0079 & 1.71 & 0.55 & -0.0073 & 1.49 & 0.48 & 0.0028 & 1.74 & 1.76 & -0.004 & 3.26 & 2.80 \\
\hline & 241 & 0 & 14.95 & 9.99 & 0 & 18.14 & 11.47 & 0 & 12.23 & 12.67 & 0 & 11.78 & 15.07 \\
\hline & 413 & 0.1156 & 5.95 & 6.34 & 0.1305 & 5.48 & 5.75 & 0.0237 & 6.90 & 6.33 & 0.0104 & 7.14 & 6.66 \\
\hline & 100 & 0 & 1.58 & 10.90 & 0 & 1.61 & 10.82 & 0 & 2.27 & 11.75 & 0 & 2.32 & 11.42 \\
\hline $\mathrm{CO}$ & 122 & 0.0059 & 1.77 & 11.15 & 0.0058 & 1.60 & 11.06 & 0.0064 & 1.97 & 10.86 & 0.0032 & 1.94 & 10.75 \\
\hline & 288 & 0 & 36.63 & 0.73 & 0 & 43.00 & 0.62 & 0 & 44.04 & 0.79 & 0 & 26.16 & 0.55 \\
\hline Benzene & 398 & 0.1721 & 6.36 & 1.09 & 0.1721 & 7.67 & 0.82 & 0.1302 & 6.36 & 1.09 & 0.0499 & 11.88 & 0.38 \\
\hline & 313 & 0 & 12.39 & 9.25 & 0 & 14.34 & 10.26 & 0 & 12.39 & 9.25 & 0 & 11.41 & 4.83 \\
\hline Toluene & 548 & 0.1632 & 10.37 & 7.49 & 0.1785 & 9.79 & 7.39 & 0.0965 & 11.37 & 7.49 & 0.0113 & 8.95 & 4.50 \\
\hline
\end{tabular}


Table 6. Average absolute deviations (\%AAD) in predictions $\left(k_{i j}=0\right)$ and calculations (using regressed $k_{i j}$ 's) of bubble pressures $\left(\Delta P^{b u b b l e}\right)$ and vapour phase compositions $\left(\Delta y_{1}\right)$ of $\mathrm{H}_{2} \mathrm{~S}+\mathrm{Comp2}$ binary systems with the SRK, PR, PC-SAFT and SAFT-VR Mie EoS.

\begin{tabular}{|c|c|c|c|c|c|c|c|c|c|c|c|c|c|}
\hline \multirow{2}{*}{ Comp2 } & \multirow{2}{*}{$\begin{array}{c}\mathrm{T}_{\text {range }} \\
{[\mathrm{K}]}\end{array}$} & \multicolumn{3}{|c|}{ SRK } & \multicolumn{3}{|c|}{ PR } & \multicolumn{3}{|c|}{ PCSAFT } & \multicolumn{3}{|c|}{ SAFT-VR Mie } \\
\hline & & $\mathrm{k}_{\mathrm{ij}}$ & $\Delta \mathrm{P}$ & $\Delta \mathrm{y}_{1}$ & $\mathrm{k}_{\mathrm{ij}}$ & $\Delta \mathrm{P}$ & $\Delta \mathrm{y}_{1}$ & $\mathrm{k}_{\mathrm{ij}}$ & $\Delta \mathrm{P}$ & $\Delta \mathrm{y}_{1}$ & $\mathrm{k}_{\mathrm{ij}}$ & $\Delta \mathrm{P}$ & $\Delta \mathrm{y}_{1}$ \\
\hline \multirow{2}{*}{$\mathrm{CO}_{2}$} & 218 & 0 & 12.23 & 4.88 & 0 & 12.94 & 4.95 & 0 & 14.13 & 5.36 & 0 & 13.86 & 5.23 \\
\hline & 301 & 0.0984 & 1.38 & 1.06 & 0.0966 & 1.43 & 1.35 & 0.0618 & 1.68 & 0.95 & 0.0621 & 1.12 & 1.89 \\
\hline \multirow{2}{*}{$\mathrm{CH}_{4}$} & 100 & 0 & 15.36 & 5.86 & 0 & 15.92 & 5.94 & 0 & 14.03 & 4.96 & 0 & 13.71 & 5.43 \\
\hline & 199 & 0.0769 & 4.93 & 2.34 & 0.0841 & 4.76 & 2.28 & 0.0386 & 4.64 & 2.10 & 0.0314 & 4.87 & 2.30 \\
\hline \multirow{2}{*}{$\mathrm{C}_{2}$} & 110 & 0 & 14.67 & 5.90 & 0 & 14.72 & 6.13 & 0 & 14.42 & 5.92 & 0 & 13.97 & 4.78 \\
\hline & 297 & 0.0871 & 4.73 & 3.27 & 0.0838 & 4.76 & 3.23 & 0.0620 & 4.41 & 3.67 & 0.0506 & 4.72 & 3.84 \\
\hline \multirow{2}{*}{$\mathrm{C}_{3}$} & 114 & 0 & 15.67 & 4.73 & 0 & 15.80 & 4.69 & 0 & 15.07 & 4.53 & 0 & 12.54 & 4.61 \\
\hline & 353 & 0.0866 & 4.49 & 1.98 & 0.0819 & 4.55 & 2.02 & 0.0576 & 4.70 & 1.77 & 0.0524 & 3.23 & 2.10 \\
\hline \multirow{2}{*}{$\mathrm{nC}_{4}$} & 239 & 0 & 16.20 & 4.61 & 0 & 16.07 & 4.72 & 0 & 14.08 & 4.59 & 0 & 11.38 & 4.36 \\
\hline & 421 & 0.1046 & 2.52 & 2.05 & 0.0891 & 2.55 & 2.09 & 0.0538 & 2.23 & 1.83 & 0.0504 & 2.10 & 2.52 \\
\hline \multirow{2}{*}{$\mathrm{iC}_{4}$} & 120 & 0 & 8.86 & 3.13 & 0 & 8.77 & 3.04 & 0 & 8.62 & 2.94 & 0 & 9.11 & 3.49 \\
\hline & 394 & 0.0631 & 2.39 & 1.84 & 0.0625 & 2.42 & 1.86 & 0.0513 & 2.27 & 1.81 & 0.0348 & 2.33 & 2.02 \\
\hline \multirow{2}{*}{$\mathrm{nC}_{5}$} & 277 & 0 & 13.83 & 4.28 & 0 & 13.61 & 4.32 & 0 & 13.29 & 4.16 & 0 & 14.54 & 4.79 \\
\hline & 447 & 0.0700 & 3.74 & 2.86 & 0.0654 & 3.50 & 2.93 & 0.0464 & 2.85 & 2.58 & 0.0455 & 3.10 & 3.13 \\
\hline \multirow{2}{*}{$\mathrm{iC}_{5}$} & 277 & 0 & 9.74 & 4.23 & 0 & 9.83 & 4.10 & 0 & 9.68 & 4.17 & 0 & 9.67 & 4.36 \\
\hline & 377 & 0.0763 & 4.23 & 2.13 & 0.0708 & 4.27 & 2.19 & 0.0480 & 3.86 & 1.94 & 0.0459 & 4.00 & 2.07 \\
\hline \multirow{2}{*}{$\mathrm{nC}_{6}$} & 233 & 0 & 12.40 & 1.76 & 0 & 11.58 & 1.71 & 0 & 11.73 & 1.60 & 0 & 10.77 & 1.59 \\
\hline & 498 & 0.0690 & 2.20 & 0.69 & 0.0575 & 2.09 & 0.83 & 0.0407 & 2.88 & 0.57 & 0.0386 & 2.35 & 0.76 \\
\hline \multirow{2}{*}{$\mathrm{nC}_{7}$} & 251 & 0 & 16.31 & 2.20 & 0 & 15.96 & 2.05 & 0 & 14.23 & 1.64 & 0 & 14.50 & 1.95 \\
\hline & 523 & 0.0736 & 5.84 & 1.38 & 0.0641 & 5.40 & 1.43 & 0.0482 & 5.28 & 1.21 & 0.0440 & 5.41 & 1.35 \\
\hline \multirow{2}{*}{$\mathrm{nC}_{9}$} & 233 & 0 & 16.45 & 1.39 & 0 & 13.47 & 1.17 & 0 & 9.30 & 1.20 & 0 & 3.47 & 1.27 \\
\hline & 543 & 0.0517 & 2.49 & 0.89 & 0.0402 & 2.18 & 0.80 & 0.0193 & 4.12 & 0.76 & 0.0082 & 2.03 & 0.89 \\
\hline \multirow{2}{*}{$\mathrm{nC}_{10}$} & 261 & 0 & 15.85 & 0.22 & 0 & 13.14 & 0.32 & 0 & 18.53 & 0.39 & 0 & 19.59 & 0.45 \\
\hline & 543 & 0.0496 & 5.30 & 0.25 & 0.0371 & 5.53 & 0.37 & 0.0390 & 4.79 & 0.22 & 0.0557 & 4.29 & 0.14 \\
\hline \multirow{2}{*}{$\mathrm{nC}_{12}$} & 263 & 0 & 5.28 & - & 0 & 4.77 & - & 0 & 24.75 & - & 0 & 20.92 & - \\
\hline & 563 & 0.0244 & 4.13 & - & 0.0106 & 4.15 & - & 0.0358 & 6.76 & - & 0.0446 & 6.13 & - \\
\hline \multirow{2}{*}{$\mathrm{nC}_{15}$} & 298 & 0 & 8.45 & - & 0 & 8.31 & - & 0 & 14.66 & - & 0 & 15.06 & - \\
\hline & 593 & 0.0097 & 7.86 & - & -0.0094 & 7.92 & - & 0.0323 & 3.32 & - & 0.0376 & 1.63 & - \\
\hline \multirow{2}{*}{$\mathrm{nC}_{20}$} & 298 & 0 & 10.47 & - & 0 & 13.31 & - & 0 & 28.05 & - & 0 & 18.36 & - \\
\hline & 434 & -0.0201 & 5.47 & - & -0.0373 & 5.88 & - & 0.0712 & 6.14 & - & 0.0429 & 5.78 & - \\
\hline \multirow{2}{*}{$\mathrm{N}_{2}$} & 200 & 0 & 34.56 & 11.90 & 0 & 37.55 & 14.25 & 0 & 31.72 & 12.18 & 0 & 24.14 & 10.88 \\
\hline & 344 & 0.1565 & 7.85 & 3.22 & 0.1738 & 5.49 & 2.80 & 0.1294 & 5.48 & 3.97 & 0.0708 & 5.28 & 2.97 \\
\hline $\mathrm{CO}$ & 100 & 0 & 24.51 & 25.50 & 0 & 30.03 & 36.62 & 0 & 18.57 & 32.96 & 0 & 19.36 & 20.29 \\
\hline e & 136 & 0.0664 & 8.80 & 11.36 & 0.0825 & 9.16 & 12.65 & 0.07648 & 8.71 & 15.85 & 0.0258 & 5.01 & 9.53 \\
\hline & 288 & 0 & 2.93 & 0.58 & 0 & 2.81 & 0.33 & 0 & 9.85 & 1.02 & 0 & 3.46 & 0.30 \\
\hline Benzene & 398 & 0.0038 & 2.38 & 0.45 & 0.0041 & 2.13 & 0.22 & 0.0107 & 7.06 & 1.11 & 0.0042 & 3.11 & 0.50 \\
\hline & 313 & 0 & 4.47 & 1.59 & 0 & 4.15 & 1.63 & 0 & 10.25 & 0.99 & 0 & 7.01 & 1.67 \\
\hline roluene & 548 & 0.0047 & 4.39 & 1.50 & 0.0032 & 4.11 & 1.57 & 0.0121 & 7.60 & 1.01 & 0.0080 & 6.46 & 1.37 \\
\hline
\end{tabular}


Table 7. Summary of the average absolute deviations (\%AAD) in bubble pressures $\left(\triangle P^{\text {bubble }}\right)$ and vapour phase compositions $\left(\Delta y_{1}\right)$ predicted $\left(k_{i j}=0\right)$ and calculated $\left(k_{i j} \neq 0\right)$ by the SRK, PR, PC-SAFT and SAFT-VR Mie EoS.

\begin{tabular}{|c|c|c|c|c|c|c|c|c|c|c|}
\hline \multirow[b]{2}{*}{ Comp1 } & \multirow[b]{2}{*}{ Comp2 } & & \multicolumn{2}{|c|}{ SRK } & \multicolumn{2}{|c|}{ PR } & \multicolumn{2}{|c|}{ PC-SAFT } & \multicolumn{2}{|c|}{ SAFT-VR Mie } \\
\hline & & & $\Delta \mathrm{P}$ & $\Delta \mathrm{y}_{1}$ & $\Delta \mathrm{P}$ & $\Delta \mathrm{y}_{1}$ & $\Delta \mathrm{P}$ & $\Delta \mathrm{y}_{1}$ & $\Delta \mathrm{P}$ & $\Delta \mathrm{y}_{1}$ \\
\hline \multirow{8}{*}{$\mathrm{CO}_{2}$} & \multirow{2}{*}{ Gases } & $\mathrm{k}_{\mathrm{ij}}=0$ & 14.92 & 6.60 & 13.47 & 6.43 & 13.85 & 6.75 & 13.99 & 7.84 \\
\hline & & $\mathrm{k}_{\mathrm{ij}} \neq 0$ & 5.04 & 4.26 & 5.49 & 3.52 & 6.55 & 4.30 & 5.72 & 3.67 \\
\hline & \multirow{2}{*}{ Alkanes } & $\mathrm{k}_{\mathrm{ij}}=0$ & 14.35 & 3.56 & 14.27 & 3.53 & 14.24 & 3.79 & 13.64 & 3.83 \\
\hline & & $\mathrm{k}_{\mathrm{ij}} \neq 0$ & 3.90 & 1.34 & 3.84 & 1.35 & 3.81 & 1.26 & 3.53 & 1.34 \\
\hline & \multirow{2}{*}{ Aromatics } & $\mathrm{k}_{\mathrm{ij}}=0$ & 23.76 & 4.16 & 24.99 & 4.21 & 36.90 & 6.80 & 20.68 & 4.06 \\
\hline & & $\mathrm{k}_{\mathrm{ij}} \neq 0$ & 6.82 & 3.60 & 6.32 & 3.54 & 11.39 & 6.58 & 8.77 & 3.71 \\
\hline & \multirow{2}{*}{ Average } & $\mathrm{k}_{\mathrm{ij}}=0$ & 15.13 & 4.23 & 14.89 & 4.18 & 15.79 & 4.68 & 14.21 & 4.66 \\
\hline & & $\mathrm{k}_{\mathrm{ij}} \neq 0$ & 4.32 & 2.15 & 4.31 & 2.00 & 4.84 & 2.40 & 4.29 & 2.04 \\
\hline \multirow{8}{*}{$\mathrm{CH}_{4}$} & \multirow{2}{*}{ Gases } & $\mathrm{k}_{\mathrm{ij}}=0$ & 16.85 & 5.07 & 17.70 & 5.39 & 13.26 & 4.99 & 5.86 & 4.66 \\
\hline & & $\mathrm{k}_{\mathrm{ij}} \neq 0$ & 3.15 & 2.68 & 3.01 & 2.35 & 4.80 & 3.56 & 3.49 & 3.47 \\
\hline & \multirow{2}{*}{ Alkanes } & $\mathrm{k}_{\mathrm{ij}}=0$ & 10.05 & 1.62 & 10.67 & 1.65 & 9.64 & 1.70 & 10.24 & 1.36 \\
\hline & & $\mathrm{k}_{\mathrm{ij}} \neq 0$ & 4.61 & 1.44 & 4.60 & 1.42 & 4.16 & 1.53 & 4.48 & 1.28 \\
\hline & \multirow{2}{*}{ Aromatics } & $\mathrm{k}_{\mathrm{ij}}=0$ & 15.48 & 4.81 & 19.06 & 4.71 & 16.07 & 4.31 & 15.25 & 2.40 \\
\hline & & $\mathrm{k}_{\mathrm{ij}} \neq 0$ & 7.09 & 4.38 & 7.51 & 4.02 & 8.48 & 3.65 & 6.91 & 2.97 \\
\hline & \multirow{2}{*}{ Average } & $\mathrm{k}_{\mathrm{ij}}=0$ & 11.91 & 3.02 & 12.79 & 3.11 & 10.95 & 2.95 & 9.93 & 2.49 \\
\hline & & $\mathrm{k}_{\mathrm{ij}} \neq 0$ & 4.54 & 2.09 & 4.53 & 1.96 & 4.62 & 2.28 & 4.49 & 2.05 \\
\hline \multirow{8}{*}{$\mathrm{C}_{2} \mathrm{H}_{6}$} & \multirow{2}{*}{ Gases } & $\mathrm{k}_{\mathrm{ij}}=0$ & 13.52 & 20.13 & 14.53 & 24.07 & 14.27 & 20.75 & 11.43 & 18.61 \\
\hline & & $\mathrm{k}_{\mathrm{ij}} \neq 0$ & 4.46 & 11.55 & 4.44 & 12.99 & 4.42 & 12.27 & 4.34 & 11.25 \\
\hline & \multirow{2}{*}{ Alkanes } & $\mathrm{k}_{\mathrm{ij}}=0$ & 4.81 & 2.02 & 4.67 & 2.04 & 8.46 & 2.21 & 12.22 & 1.97 \\
\hline & & $\mathrm{k}_{\mathrm{ij}} \neq 0$ & 3.54 & 1.95 & 3.51 & 2.00 & 3.52 & 1.89 & 3.34 & 1.73 \\
\hline & Aromatics & $\mathrm{k}_{\mathrm{ij}}=0$ & 7.25 & 3.31 & 8.33 & 3.22 & 9.26 & 4.47 & 5.93 & 2.25 \\
\hline & Aromatics & $\mathrm{k}_{\mathrm{ij}} \neq 0$ & 5.26 & 3.03 & 4.89 & 2.47 & 4.88 & 2.78 & 4.77 & 2.66 \\
\hline & Average & $\mathrm{k}_{\mathrm{ij}}=0$ & 6.92 & 7.50 & 7.13 & 8.66 & 9.79 & 7.93 & 11.50 & 6.90 \\
\hline & Average & $\mathrm{k}_{\mathrm{ij}} \neq 0$ & 3.89 & 4.90 & 3.83 & 5.29 & 3.83 & 5.05 & 3.68 & 4.64 \\
\hline & Gases & $\mathrm{k}_{\mathrm{ij}}=0$ & 12.88 & 6.69 & 13.65 & 7.09 & 12.98 & 7.10 & 14.16 & 8.60 \\
\hline & Gases & $\mathrm{k}_{\mathrm{ij}} \neq 0$ & 3.79 & 4.36 & 3.41 & 4.02 & 4.50 & 4.32 & 4.85 & 4.72 \\
\hline & & $\mathrm{k}_{\mathrm{ij}}=0$ & 19.43 & 3.49 & 20.69 & 3.52 & 22.75 & 3.91 & 15.77 & 4.23 \\
\hline & Alkanes & $\mathrm{k}_{\mathrm{ij}} \neq 0$ & 5.79 & 2.50 & 5.51 & 2.15 & 5.93 & 2.29 & 5.89 & 2.90 \\
\hline $\mathbf{N}_{2}$ & Aromatics & $\mathrm{k}_{\mathrm{ij}}=0$ & 24.51 & 4.99 & 28.67 & 5.44 & 28.21 & 5.02 & 18.79 & 2.69 \\
\hline & Aromatics & $\mathrm{k}_{\mathrm{ij}} \neq 0$ & 8.36 & 4.29 & 8.73 & 4.10 & 8.86 & 4.29 & 10.41 & 2.44 \\
\hline & Average & $\mathrm{k}_{\mathrm{ij}}=0$ & 17.72 & 4.54 & 19.07 & 4.72 & 20.04 & 4.93 & 14.93 & 5.33 \\
\hline & & $\mathrm{k}_{\mathrm{ij}} \neq 0$ & 5.51 & 3.20 & 5.22 & 2.87 & 5.70 & 3.06 & 5.86 & 3.37 \\
\hline & & $\mathrm{k}_{\mathrm{ij}}=0$ & 23.77 & 14.09 & 26.84 & 18.61 & 21.47 & 16.83 & 19.12 & 12.13 \\
\hline & Gases & $\mathrm{k}_{\mathrm{ij}} \neq 0$ & 6.01 & 5.21 & 5.36 & 5.60 & 5.29 & 6.92 & 3.80 & 4.80 \\
\hline & $\Delta 1$ kanes & $\mathrm{k}_{\mathrm{ij}}=0$ & 11.97 & 3.19 & 11.68 & 3.18 & 14.03 & 3.01 & 12.51 & 3.09 \\
\hline $\mathrm{H}_{2} \mathrm{~S}$ & Alkanes & $\mathrm{k}_{\mathrm{ij}} \neq 0$ & 4.02 & 1.64 & 4.00 & 1.67 & 3.88 & 1.54 & 3.46 & 1.76 \\
\hline $\mathrm{H}_{2} \mathrm{~S}$ & Aromatics & $\mathrm{k}_{\mathrm{ij}}=0$ & 29.53 & 18.70 & 33.79 & 25.43 & 25.15 & 22.57 & 21.75 & 15.59 \\
\hline & Aromatics & $\mathrm{k}_{\mathrm{ij}} \neq 0$ & 8.32 & 7.29 & 7.33 & 7.73 & 7.10 & 9.91 & 5.15 & 6.25 \\
\hline & Average & $\mathrm{k}_{\mathrm{ij}}=0$ & 12.91 & 4.87 & 13.14 & 5.65 & 14.75 & 5.21 & 12.77 & 4.44 \\
\hline & Average & $\mathrm{k}_{\mathrm{ij}} \neq 0$ & 4.26 & 2.19 & 4.11 & 2.27 & 4.44 & 2.43 & 3.65 & 2.20 \\
\hline & Gases & $\mathrm{k}_{\mathrm{ij}}=0$ & 14.97 & 10.39 & 15.56 & 12.10 & 13.44 & 11.13 & 11.06 & 10.25 \\
\hline & Gases & $\mathrm{k}_{\mathrm{ij}} \neq 0$ & 4.38 & 5.76 & 4.27 & 5.97 & 5.08 & 6.52 & 4.42 & 5.91 \\
\hline & Alkanes & $\mathrm{k}_{\mathrm{ij}}=0$ & 13.16 & 2.99 & 13.47 & 2.99 & 14.90 & 3.14 & 13.94 & 3.16 \\
\hline Overall & Alkanes & $\mathrm{k}_{\mathrm{ij}} \neq 0$ & 4.76 & 1.93 & 4.68 & 1.86 & 4.60 & 1.79 & 4.48 & 1.90 \\
\hline Overan & Aromatics & $\mathrm{k}_{\mathrm{ij}}=0$ & 14.94 & 3.67 & 16.91 & 3.71 & 20.10 & 4.32 & 13.18 & 2.48 \\
\hline & Aromatics & $\mathrm{k}_{\mathrm{ij}} \neq 0$ & 6.18 & 3.25 & 6.11 & 3.01 & 8.19 & 3.67 & 7.13 & 2.54 \\
\hline & A yerage & $\mathrm{k}_{\mathrm{ij}}=0$ & 13.68 & 4.92 & 14.19 & 5.36 & 15.10 & 5.29 & 13.31 & 4.85 \\
\hline & Average & $\mathrm{k}_{\mathrm{ij}} \neq 0$ & 4.82 & 3.05 & 4.73 & 3.03 & 5.03 & 3.21 & 4.71 & 2.98 \\
\hline
\end{tabular}


Table 8. Average absolute binary interaction parameters and average sensitivities in the VLE calculations.

\begin{tabular}{lcccc}
\hline & SRK & PR & PC-SAFT & SAFT-VR Mie \\
\hline$|\overline{\boldsymbol{B I P}}|$ & 0.0680 & 0.0677 & 0.0445 & 0.0313 \\
Sensitivity in $\Delta \mathrm{P}(\%)$ & 137.4 & 140 & 270.2 & 294.7 \\
Sensitivity in $\Delta \mathrm{y}_{1}(\%)$ & 24.5 & 28.7 & 52.1 & 76.9 \\
\hline
\end{tabular}


Table 9. Critical properties of $\mathrm{CO}_{2}$ predicted with PC-SAFT and SAFT-VR Mie and comparison with experimental data.

\begin{tabular}{lccccc}
\hline Critical & \multirow{2}{*}{$\begin{array}{c}\text { Exp } \\
\text { property }\end{array}$} & {$[44]$} & \multicolumn{2}{c}{ PC-SAFT } & \multicolumn{2}{c}{ SAFT-VR Mie } \\
\cline { 3 - 6 } & & value & \%AAD & Value & \%AAD \\
\hline $\mathrm{T}_{\mathrm{c}} / \mathrm{K}$ & 304.1 & 309.4 & 1.73 & 307.2 & 0.99 \\
$\mathrm{P}_{\mathrm{c}} / \mathrm{MPa}$ & 7.38 & 7.92 & 7.32 & 7.81 & 5.43 \\
$\rho_{\mathrm{c}} / \mathrm{kg} \cdot \mathrm{m}^{-3}$ & 467.6 & 482.5 & 3.19 & 473.1 & 1.18 \\
\hline
\end{tabular}


Table 10. Average (AAD\%) and maximum (MAD\%) absolute deviations in correlated single-phase fluid density by the SRK, SRK + VC, PR, PR + VC, PC-SAFT and SAFT-VR Mie models within 253-523K and 0-150MPa.

\begin{tabular}{|c|c|c|c|c|c|c|c|c|c|c|c|c|}
\hline \multirow[b]{3}{*}{ Components } & \multicolumn{4}{|c|}{ SRK } & \multicolumn{4}{|c|}{ PR } & \multirow{2}{*}{\multicolumn{2}{|c|}{ PC-SAFT }} & \multirow{2}{*}{\multicolumn{2}{|c|}{ SAFT-VR Mie }} \\
\hline & \multicolumn{2}{|c|}{ without VC } & \multicolumn{2}{|c|}{ with VC } & \multicolumn{2}{|c|}{ without VC } & \multicolumn{2}{|c|}{ with VC } & & & & \\
\hline & $\mathrm{AAD} \%$ & MAD $\%$ & $\mathrm{AAD} \%$ & MAD\% & $\mathrm{AAD} \%$ & MAD\% & $\mathrm{AAD} \%$ & MAD\% & $\mathrm{AAD} \%$ & MAD\% & $\mathrm{AAD} \%$ & MAD $\%$ \\
\hline $\mathrm{C}_{1}$ & 1.28 & 6.08 & 1.26 & 6.17 & 7.09 & 11.90 & 0.92 & 3.79 & 1.45 & 2.48 & 0.95 & 1.94 \\
\hline $\mathrm{C}_{2}$ & 2.37 & 15.13 & 1.71 & 15.90 & 7.82 & 11.64 & 2.54 & 10.72 & 1.98 & 4.05 & 0.41 & 6.26 \\
\hline $\mathrm{C}_{3}$ & 4.19 & 20.17 & 2.33 & 18.06 & 7.54 & 12.42 & 3.07 & 14.40 & 1.88 & 13.77 & 0.53 & 6.69 \\
\hline $\mathrm{iC}_{4}$ & 4.42 & 21.08 & 2.28 & 18.90 & 6.73 & 13.41 & 2.26 & 15.12 & 1.15 & 8.64 & 0.71 & 8.26 \\
\hline $\mathrm{nC}_{4}$ & 5.66 & 15.59 & 2.12 & 16.30 & 6.37 & 10.46 & 2.15 & 11.72 & 1.71 & 5.70 & 0.95 & 6.85 \\
\hline $\mathrm{iC}_{5}$ & 5.90 & 18.97 & 2.00 & 19.86 & 5.48 & 12.67 & 1.92 & 12.86 & 1.68 & 9.80 & 0.83 & 13.19 \\
\hline $\mathrm{nC}_{5}$ & 7.85 & 20.61 & 2.18 & 20.79 & 4.73 & 14.60 & 2.17 & 15.47 & 1.36 & 15.31 & 0.96 & 14.02 \\
\hline $\mathrm{nC}_{6}$ & 9.74 & 22.53 & 2.17 & 20.91 & 4.50 & 15.09 & 2.22 & 15.80 & 1.76 & 14.30 & 1.14 & 12.37 \\
\hline $\mathrm{nC}_{7}$ & 11.66 & 20.94 & 2.14 & 16.52 & 4.81 & 11.97 & 2.16 & 12.39 & 1.93 & 8.31 & 1.38 & 9.80 \\
\hline $\mathrm{nC}_{8}$ & 13.82 & 21.85 & 2.16 & 13.11 & 5.47 & 14.05 & 2.18 & 9.14 & 2.10 & 7.86 & 1.53 & 10.74 \\
\hline $\mathrm{nC}_{9}$ & 15.95 & 24.02 & 2.20 & 10.37 & 7.16 & 16.63 & 2.15 & 7.57 & 2.45 & 8.19 & 1.66 & 9.31 \\
\hline $\mathrm{nC}_{10}$ & 17.68 & 25.72 & 2.25 & 9.68 & 9.30 & 18.74 & 2.19 & 6.83 & 2.38 & 8.68 & 1.61 & 9.57 \\
\hline $\mathrm{nC}_{12}$ & 19.83 & 27.96 & 2.37 & 7.90 & 12.89 & 21.38 & 2.28 & 5.65 & 2.44 & 9.63 & 1.74 & 10.09 \\
\hline $\mathrm{CO}_{2}$ & 2.84 & 8.82 & 1.83 & 15.85 & 8.25 & 11.09 & 1.23 & 13.60 & 0.73 & 8.48 & 1.62 & 5.11 \\
\hline $\mathrm{N}_{2}$ & 1.96 & 8.40 & 1.08 & 8.45 & 7.46 & 12.91 & 1.03 & 4.63 & 1.14 & 4.38 & 0.61 & 2.94 \\
\hline $\mathrm{O}_{2}$ & 1.49 & 3.83 & 1.32 & 3.91 & 5.67 & 12.15 & 0.97 & 2.36 & 1.54 & 3.24 & 0.50 & 2.18 \\
\hline $\mathrm{Ar}$ & 1.35 & 3.34 & 1.06 & 4.05 & 6.69 & 12.78 & 0.72 & 1.48 & 1.05 & 2.86 & 1.18 & 2.39 \\
\hline $\mathrm{CO}$ & 2.05 & 3.93 & 1.11 & 4.82 & 7.27 & 13.21 & 0.99 & 1.90 & 1.90 & 4.31 & 0.84 & 1.77 \\
\hline $\mathrm{H}_{2} \mathrm{~S}$ & 3.84 & 14.46 & 2.34 & 13.78 & 6.23 & 10.96 & 2.06 & 11.93 & 0.73 & 12.89 & 1.99 & 10.75 \\
\hline $\mathrm{SO}_{2}$ & 8.01 & 21.27 & 3.86 & 17.05 & 1.63 & 13.53 & 2.62 & 14.65 & 1.99 & 10.81 & 1.71 & 8.60 \\
\hline Benzene & 9.15 & 14.22 & 2.79 & 12.13 & 6.90 & 12.84 & 2.58 & 7.91 & 1.10 & 4.84 & 1.35 & 7.64 \\
\hline Toluene & 11.72 & 15.70 & 2.83 & 10.41 & 6.75 & 11.57 & 2.47 & 8.28 & 0.97 & 2.96 & 1.26 & 8.11 \\
\hline Average & 7.40 & 16.12 & 2.06 & 12.95 & 6.67 & 13.45 & 1.95 & 9.46 & 1.61 & 7.80 & 1.16 & 7.66 \\
\hline
\end{tabular}


Table 11. Deviations in calculated density of $\mathrm{CO}_{2}+\mathrm{Comp2}$ systems by the SRK, PR, PC-SAFT and SAFTVR Mie EoSs with and without volume correction (VC).

\begin{tabular}{|c|c|c|c|c|c|c|c|c|c|c|c|c|c|}
\hline \multirow{3}{*}{$\begin{array}{l}\text { Comp2 } \\
\mathrm{C}_{1}\end{array}$} & \multirow{3}{*}{$\begin{array}{l}\text { No } \\
\text { Data } \\
1312\end{array}$} & \multicolumn{6}{|c|}{ Ranges } & \multicolumn{2}{|c|}{ SRK } & \multicolumn{2}{|c|}{ PR } & \multirow{3}{*}{$\begin{array}{c}\text { PC-SAFT } \\
3.08\end{array}$} & \multirow{3}{*}{$\begin{array}{c}\text { SAFT-Mie } \\
2.57\end{array}$} \\
\hline & & \multicolumn{2}{|c|}{$\mathrm{T}[\mathrm{K}]$} & \multicolumn{2}{|c|}{$\mathrm{P}[\mathrm{MPa}]$} & \multicolumn{2}{|c|}{$\mathrm{x}_{\mathrm{CO} 2}$} & \multirow{2}{*}{$\frac{\text { no VC }}{3.76}$} & \multirow{2}{*}{$\frac{\mathrm{VC}}{2.67}$} & \multirow{2}{*}{$\frac{\text { no } \mathrm{VC}}{4.11}$} & \multirow{2}{*}{$\frac{\mathrm{VC}}{2.62}$} & & \\
\hline & & 219 & 673 & 0.1 & 100.0 & 0.10 & 0.90 & & & & & & \\
\hline $\mathrm{C}_{2}$ & 1607 & 210 & 477 & 1.7 & 69.0 & 0.17 & 0.98 & 7.00 & 6.22 & 8.07 & 6.79 & 6.27 & 5.57 \\
\hline $\mathrm{C}_{3}$ & 1269 & 294 & 510 & 2.5 & 70.6 & 0.03 & 0.98 & 4.57 & 4.12 & 7.31 & 3.51 & 4.12 & 2.93 \\
\hline $\mathrm{iC}_{4}$ & 346 & 280 & 440 & 3 & 200.0 & 0.24 & 0.97 & 4.05 & 1.07 & 5.70 & 1.50 & 4.87 & 1.92 \\
\hline $\mathrm{nC}_{4}$ & 345 & 280 & 440 & 0.4 & 200.0 & 0.01 & 0.97 & 3.88 & 2.25 & 5.14 & 1.10 & 2.87 & 2.17 \\
\hline $\mathrm{nC}_{5}$ & 358 & 307 & 323 & 2.5 & 35.0 & 0.21 & 0.99 & 9.73 & 4.91 & 5.85 & 5.31 & 2.45 & 1.99 \\
\hline $\mathrm{nC}_{6}$ & 176 & 308 & 313 & 6.3 & 12.5 & 0.05 & 0.98 & 8.17 & 5.10 & 6.74 & 5.39 & 3.18 & 2.83 \\
\hline $\mathrm{nC}_{7}$ & 558 & 220 & 459 & 0.1 & 55.5 & 0.02 & 0.99 & 8.65 & 5.22 & 7.02 & 5.46 & 3.09 & 2.65 \\
\hline $\mathrm{nC}_{8}$ & 24 & 308 & 308 & 12.0 & 35.0 & 0.93 & 0.97 & 3.91 & 1.63 & 3.33 & 1.95 & 3.80 & 2.43 \\
\hline $\mathrm{nC}_{10}$ & 792 & 283 & 555 & 0.10 & 120.0 & 0.03 & 0.94 & 7.86 & 4.00 & 4.43 & 2.17 & 1.46 & 1.23 \\
\hline $\mathrm{C}_{14} *$ & 40 & 323 & 344 & 1.0 & 6.0 & 0.10 & 0.99 & 12.00 & 5.01 & 12.51 & 2.60 & 1.63 & 1.90 \\
\hline $\mathrm{C}_{16} *$ & 8 & 313 & 313 & 1.6 & 6.0 & 0.19 & 0.59 & 25.26 & 1.79 & 17.94 & 2.03 & 0.89 & 1.01 \\
\hline $\mathrm{C}_{20} *$ & 60 & 310 & 373 & 0.5 & 7.6 & 0.04 & 0.68 & 21.48 & 8.64 & 19.42 & 6.32 & 0.92 & 1.10 \\
\hline $\mathrm{H}_{2} \mathrm{~S}$ & 540 & 249 & 500 & 1.5 & 60.0 & 0.06 & 0.94 & 3.72 & 1.91 & 3.47 & 1.87 & 3.25 & 1.84 \\
\hline $\mathrm{N}_{2}$ & 2034 & 225 & 673 & 4.0 & 800.0 & 0.10 & 0.99 & 9.34 & 3.67 & 10.67 & 3.58 & 3.50 & 2.98 \\
\hline $\mathrm{O}_{2}$ & 230 & 273 & 383 & 4.0 & 20.0 & 0.85 & 0.95 & 5.37 & 3.92 & 6.16 & 3.84 & 3.14 & 2.28 \\
\hline $\mathrm{CO}$ & 53 & 308 & 343 & 22.5 & 47.0 & 0.86 & 0.95 & 1.80 & 1.78 & 1.84 & 1.75 & 1.70 & 2.17 \\
\hline $\mathrm{Ar}$ & 458 & 250 & 501 & 1 & 61.0 & 0.05 & 0.94 & 9.67 & 5.88 & 9.80 & 5.90 & 5.96 & 5.68 \\
\hline Toluene & 360 & 291 & 423 & 1.1 & 67.1 & 0.12 & 0.90 & 8.08 & 5.76 & 7.91 & 6.32 & 8.12 & 7.17 \\
\hline
\end{tabular}

* Only saturated-liquid density data 
Table 12. Deviations in calculated density of $\mathrm{CH}_{4}+$ Comp2 systems by the SRK, PR, PC-SAFT and SAFTVR Mie EoSs with and without volume correction (VC).

\begin{tabular}{|c|c|c|c|c|c|c|c|c|c|c|c|c|c|}
\hline \multirow{3}{*}{$\begin{array}{l}\text { Comp2 } \\
\mathrm{C}_{2}\end{array}$} & \multirow{3}{*}{$\begin{array}{l}\begin{array}{l}\text { No } \\
\text { Data }\end{array} \\
833\end{array}$} & \multicolumn{6}{|c|}{ Ranges } & \multicolumn{2}{|c|}{ SRK } & \multicolumn{2}{|c|}{ PR } & \multirow{3}{*}{$\begin{array}{c}\text { PC-SAFT } \\
3.42\end{array}$} & \multirow{3}{*}{$\frac{\text { SAFT-Mie }}{2.60}$} \\
\hline & & \multicolumn{2}{|c|}{$\mathrm{T}[\mathrm{K}]$} & \multicolumn{2}{|c|}{$\mathrm{P}[\mathrm{MPa}]$} & \multicolumn{2}{|c|}{$\mathrm{x}_{\mathrm{CH} 4}$} & \multirow{2}{*}{$\frac{\text { no VC }}{4.90}$} & \multirow{2}{*}{$\frac{\mathrm{VC}}{4.09}$} & \multirow{2}{*}{$\frac{\text { no VC }}{4.98}$} & \multirow{2}{*}{$\frac{\mathrm{VC}}{3.81}$} & & \\
\hline & & 100 & 394 & 0.1 & 35.8 & 0.10 & 0.92 & & & & & & \\
\hline $\mathrm{C}_{3}$ & 2686 & 100 & 510 & 0.1 & 68.9 & 0.01 & 0.97 & 4.90 & 3.44 & 5.17 & 2.88 & 2.19 & 2.04 \\
\hline $\mathrm{iC}_{4}$ & 136 & 100 & 256 & 0.1 & 16.5 & 0.18 & 0.94 & 5.86 & 1.75 & 5.68 & 2.96 & 0.76 & 0.64 \\
\hline $\mathrm{nC}_{4}$ & 138 & 100 & 479 & 0.1 & 31.0 & 0.15 & 0.95 & 7.80 & 2.05 & 7.07 & 2.12 & 1.83 & 1.66 \\
\hline $\mathrm{nC}_{5}$ & 580 & 310 & 511 & 2.7 & 34.5 & 0.03 & 0.93 & 6.94 & 2.61 & 7.36 & 2.53 & 2.24 & 2.00 \\
\hline $\mathrm{nC}_{7}$ & 827 & 185 & 510 & 0.4 & 69.8 & 0.10 & 0.75 & 8.16 & 3.85 & 7.92 & 3.96 & 3.70 & 3.53 \\
\hline $\mathrm{nC}_{10}$ & 922 & 293 & 444 & 0.1 & 140.0 & 0.09 & 0.96 & 7.91 & 3.69 & 7.33 & 3.73 & 3.66 & 3.60 \\
\hline $\mathrm{C}_{14} *$ & 24 & 294 & 448 & 2.0 & 9.5 & 0.08 & 0.36 & 17.12 & 6.09 & 11.57 & 3.24 & 0.80 & 1.15 \\
\hline $\mathrm{C}_{18} *$ & 24 & 323 & 448 & 1.9 & 8.7 & 0.08 & 0.36 & 21.37 & 7.36 & 16.3 & 6.52 & 0.87 & 1.15 \\
\hline $\mathrm{C}_{20} *$ & 12 & 313 & 313 & 0.3 & 5.0 & 0.02 & 0.27 & 19.35 & 11.66 & 27.94 & 13.22 & 0.79 & 1.17 \\
\hline $\mathrm{CO}_{2}$ & 1452 & 219 & 673 & 0.1 & 100 & 0.02 & 0.90 & 3.76 & 2.67 & 4.11 & 2.62 & 3.08 & 2.57 \\
\hline $\mathrm{H}_{2} \mathrm{~S}$ & 1220 & 277 & 501 & 0.8 & 69.0 & 0.10 & 0.90 & 9.72 & 5.54 & 9.85 & 5.39 & 5.20 & 4.97 \\
\hline $\mathrm{N}_{2}$ & 1868 & 100 & 673 & 0.1 & 138.0 & 0.01 & 0.99 & 2.32 & 1.85 & 2.97 & 1.27 & 2.14 & 0.90 \\
\hline $\mathrm{CO}$ & 112 & 116 & 125 & 2.0 & 160.0 & 0.20 & 0.71 & 5.76 & 1.40 & 12.14 & 1.53 & 1.29 & 1.04 \\
\hline $\mathrm{Ar}$ & 259 & 100 & 423 & 0.1 & 138 & 0.08 & 0.85 & 0.98 & 1.06 & 12.87 & 2.26 & 0.62 & 0.53 \\
\hline Toluene & 392 & 185 & 373 & 0.1 & 140 & 0.04 & 0.95 & 5.80 & 3.27 & 5.90 & 3.12 & 1.84 & 1.27 \\
\hline
\end{tabular}


Table 13. Deviations in calculated density of $\mathrm{C}_{2} \mathrm{H}_{6}+$ Comp2 systems by the SRK, PR, PC-SAFT and SAFT-VR Mie EoSs with and without volume correction (VC).

\begin{tabular}{|c|c|c|c|c|c|c|c|c|c|c|c|c|c|}
\hline \multirow{3}{*}{$\begin{array}{l}\text { Comp2 } \\
C_{1}\end{array}$} & \multirow{3}{*}{$\begin{array}{l}\text { No } \\
\text { Data } \\
833\end{array}$} & \multicolumn{6}{|c|}{ Ranges } & \multicolumn{2}{|c|}{ SRK } & \multicolumn{2}{|c|}{ PR } & \multirow{2}{*}{ PC-SAFT } & \multirow{2}{*}{ SAFT-Mie } \\
\hline & & \multicolumn{2}{|c|}{$\mathrm{T}[\mathrm{K}]$} & \multicolumn{2}{|c|}{$\mathrm{P}[\mathrm{MPa}]$} & \multicolumn{2}{|c|}{$\mathrm{x}_{\mathrm{C} 2 \mathrm{H} 6}$} & \multirow{2}{*}{$\frac{\text { no VC }}{4.90}$} & \multirow{2}{*}{$\frac{\mathrm{VC}}{4.09}$} & \multirow{2}{*}{$\frac{\text { no } \mathrm{VC}}{4.98}$} & \multirow{2}{*}{$\frac{\mathrm{VC}}{3.81}$} & & \\
\hline & & 100 & 394 & 0.1 & 35.8 & 0.10 & 0.92 & & & & & 3.42 & 2.60 \\
\hline $\mathrm{C}_{3}$ & 1462 & 102 & 400 & 1.5 & 34.6 & 0.01 & 0.95 & 7.27 & 4.31 & 5.13 & 3.66 & 0.80 & 0.64 \\
\hline $\mathrm{iC}_{4} *$ & 6 & 115 & 130 & 0.0 & 0.0 & 0.69 & 0.72 & 6.09 & 3.58 & 5.31 & 5.22 & 0.45 & 1.06 \\
\hline $\mathrm{nC}_{4}$ & 12 & 311 & 311 & 3.4 & 13.8 & 0.25 & 0.78 & 7.63 & 2.17 & 4.02 & 2.79 & 1.25 & 0.42 \\
\hline $\mathrm{nC}_{5}$ & 57 & 309 & 309 & 3.1 & 7.1 & 0.68 & 0.99 & 13.39 & 9.05 & 10.51 & 7.30 & 2.13 & 2.62 \\
\hline $\mathrm{nC}_{7}$ & 30 & 185 & 353 & 0.1 & 7.5 & 0.02 & 0.68 & 11.34 & 1.98 & 8.12 & 1.31 & 0.92 & 0.89 \\
\hline $\mathrm{nC}_{10}$ & 1366 & 278 & 511 & 1.4 & 68.9 & 0.10 & 0.90 & 11.04 & 2.51 & 7.06 & 1.94 & 0.59 & 0.81 \\
\hline $\mathrm{C}_{16} *$ & 29 & 313 & 353 & 4.7 & 10.4 & 0.88 & 0.99 & 24.60 & 18.44 & 19.90 & 18.10 & 11.74 & 12.14 \\
\hline $\mathrm{C}_{20} *$ & 29 & 323 & 423 & 0.9 & 7.8 & 0.10 & 0.84 & 19.08 & 10.70 & 13.56 & 11.43 & 1.74 & 3.02 \\
\hline $\mathrm{CO}_{2}$ & 1607 & 210 & 477 & 1.7 & 69.0 & 0.17 & 0.98 & 7.00 & 6.22 & 8.07 & 6.79 & 6.27 & 5.57 \\
\hline $\mathrm{H}_{2} \mathrm{~S}$ & 357 & 254 & 363 & 1.6 & 21.5 & 0.02 & 0.96 & 6.09 & 3.05 & 5.08 & 3.35 & 2.93 & 1.96 \\
\hline $\mathrm{N}_{2}$ & 373 & 113 & 477 & 2.0 & 62.0 & 0.25 & 0.99 & 3.49 & 2.17 & 2.82 & 1.69 & 1.47 & 0.58 \\
\hline $\mathrm{CO}$ & 5 & 303 & 343 & 8.1 & 10.6 & 0.42 & 0.48 & 2.93 & 2.19 & 1.00 & 0.98 & 2.29 & 0.87 \\
\hline
\end{tabular}


Table 14. Deviations in calculated density of $\mathrm{N}_{2}+$ Comp2 systems by the SRK, PR, PC-SAFT and SAFTVR Mie EoSs with and without volume correction (VC).

\begin{tabular}{|c|c|c|c|c|c|c|c|c|c|c|c|c|c|}
\hline \multirow{3}{*}{$\begin{array}{l}\text { Comp2 } \\
C_{1}\end{array}$} & \multirow{3}{*}{$\begin{array}{l}\text { No } \\
\text { Data } \\
1868\end{array}$} & \multicolumn{6}{|c|}{ Ranges } & \multicolumn{2}{|c|}{ SRK } & \multicolumn{2}{|c|}{ PR } & \multirow{2}{*}{ PC-SAFT } & \multirow{2}{*}{ SAFT-Mie } \\
\hline & & \multicolumn{2}{|c|}{$\mathrm{T}[\mathrm{K}]$} & \multicolumn{2}{|c|}{$\mathrm{P}[\mathrm{MPa}]$} & \multicolumn{2}{|c|}{$\mathrm{x}_{\mathrm{N} 2}$} & \multirow{2}{*}{$\frac{\text { no VC }}{2.32}$} & \multirow{2}{*}{$\frac{\mathrm{VC}}{1.85}$} & \multirow{2}{*}{$\frac{\text { no } \mathrm{VC}}{2.97}$} & \multirow{2}{*}{$\frac{\mathrm{VC}}{1.27}$} & & \\
\hline & & 100 & 673 & 0.1 & 138.0 & 0.01 & 0.99 & & & & & 2.14 & 0.90 \\
\hline $\mathrm{C}_{2}$ & 373 & 113 & 477 & 2.0 & 62.0 & 0.01 & 0.75 & 3.49 & 2.17 & 2.82 & 1.69 & 1.47 & 0.58 \\
\hline $\mathrm{C}_{3}$ & 23 & 399 & 422 & 8.6 & 42.1 & 0.01 & 0.83 & 8.89 & 7.92 & 12.35 & 8.72 & 7.79 & 6.72 \\
\hline $\mathrm{nC}_{4}$ & 493 & 428 & 478 & 6.0 & 68.9 & 0.10 & 0.91 & 4.97 & 2.13 & 5.62 & 1.69 & 3.01 & 1.21 \\
\hline $\mathrm{nC}_{8}$ & 144 & 293 & 373 & 25.0 & 100.0 & 0.79 & 0.79 & 10.12 & 3.66 & 2.37 & 1.12 & 0.83 & 0.66 \\
\hline $\mathrm{nC}_{10}$ & 8 & 313 & 313 & 0.1 & 40.1 & 0.01 & 0.38 & 16.36 & 3.35 & 6.32 & 0.87 & 0.43 & 0.48 \\
\hline $\mathrm{CO}_{2}$ & 2034 & 225 & 673 & 4.0 & 800.0 & 0.01 & 0.90 & 9.34 & 3.67 & 10.67 & 3.58 & 3.50 & 2.98 \\
\hline $\mathrm{H}_{2} \mathrm{~S}$ & 47 & 293 & 373 & 10.3 & 24.1 & 0.78 & 0.91 & 1.45 & 0.92 & 2.62 & 0.65 & 2.06 & 0.78 \\
\hline $\mathrm{O}_{2}$ & 2 & 100 & 100 & 0.1 & 0.1 & 0.68 & 0.82 & 3.31 & 1.10 & 9.53 & 2.02 & 1.81 & 0.98 \\
\hline $\mathrm{Ar}$ & 565 & 100 & 423 & 2.7 & 800.0 & 0.16 & 0.80 & 1.37 & 1.00 & 3.43 & 0.96 & 1.18 & 0.92 \\
\hline $\mathrm{CO}$ & 109 & 250 & 400 & 8.0 & 20.0 & 0.90 & 0.95 & 1.73 & 1.22 & 1.94 & 0.35 & 1.62 & 0.09 \\
\hline
\end{tabular}


Table 15. Deviations in calculated density of $\mathrm{H}_{2} \mathrm{~S}+$ Comp2 systems by the SRK, PR, PC-SAFT and SAFTVR Mie EoSs with and without volume correction (VC).

\begin{tabular}{|c|c|c|c|c|c|c|c|c|c|c|c|c|c|}
\hline \multirow{3}{*}{$\begin{array}{l}\text { Comp2 } \\
\mathrm{C}_{1}\end{array}$} & \multirow{3}{*}{$\begin{array}{l}\text { No } \\
\text { Data } \\
1220\end{array}$} & \multicolumn{6}{|c|}{ Ranges } & \multicolumn{2}{|c|}{ SRK } & \multicolumn{2}{|c|}{ PR } & \multirow{3}{*}{$\begin{array}{c}\text { PC-SAFT } \\
5.20\end{array}$} & \multirow{3}{*}{$\begin{array}{c}\text { SAFT-Mie } \\
4.97\end{array}$} \\
\hline & & \multicolumn{2}{|c|}{$\mathrm{T}[\mathrm{K}]$} & \multicolumn{2}{|c|}{$\mathrm{P}[\mathrm{MPa}]$} & \multicolumn{2}{|c|}{$\mathrm{x}_{\mathrm{H} 2 \mathrm{~S}}$} & \multirow{2}{*}{$\frac{\text { no VC }}{9.72}$} & \multirow{2}{*}{$\frac{\mathrm{VC}}{5.54}$} & \multirow{2}{*}{$\frac{\text { no VC }}{9.85}$} & \multirow{2}{*}{$\frac{\mathrm{VC}}{5.39}$} & & \\
\hline & & 277 & 501 & 0.8 & 69.0 & 0.10 & 0.90 & & & & & & \\
\hline $\mathrm{C}_{2}$ & 357 & 254 & 363 & 1.6 & 21.5 & 0.04 & 0.98 & 6.09 & 3.15 & 5.08 & 3.35 & 2.93 & 1.96 \\
\hline $\mathrm{C}_{3}$ & 135 & 263 & 363 & 4.354 & 34.7 & 0.27 & 0.90 & 9.15 & 6.24 & 7.31 & 6.00 & 8.33 & 5.35 \\
\hline $\mathrm{nC}_{5}$ & 520 & 278 & 511 & 1.4 & 68.9 & 0.25 & 0.80 & 8.24 & 2.94 & 3.67 & 2.49 & 1.61 & 0.64 \\
\hline $\mathrm{nC}_{10}$ & 481 & 278 & 444 & 1.40 & 69.0 & 0.23 & 0.81 & 19.66 & 3.65 & 10.01 & 5.54 & 3.30 & 3.08 \\
\hline $\mathrm{CO}_{2}$ & 540 & 249 & 500 & 1.5 & 60.0 & 0.06 & 0.94 & 3.72 & 1.81 & 3.47 & 1.77 & 3.25 & 1.84 \\
\hline $\mathrm{N}_{2}$ & 47 & 293 & 373 & 10.3 & 24.1 & 0.09 & 0.22 & 1.45 & 0.92 & 2.62 & 0.65 & 2.06 & 0.78 \\
\hline Toluene & 116 & 373 & 501 & 9 & 65 & 0.92 & 0.92 & 7.93 & 6.71 & 7.13 & 7.02 & 8.21 & 8.42 \\
\hline
\end{tabular}



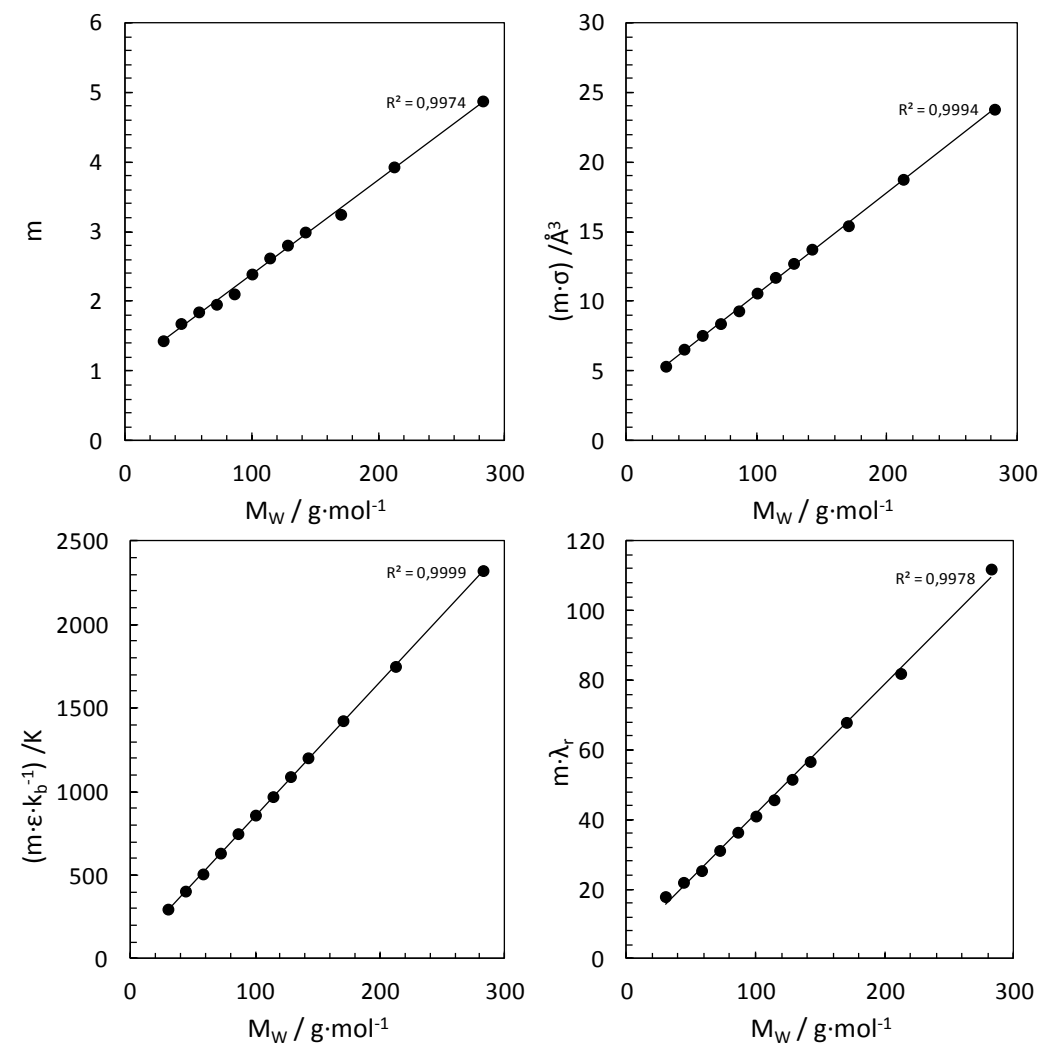

Figure 1. Correlations of the SAFT-VR Mie molecular parameters for the series of $\boldsymbol{n}$-alkanes. 

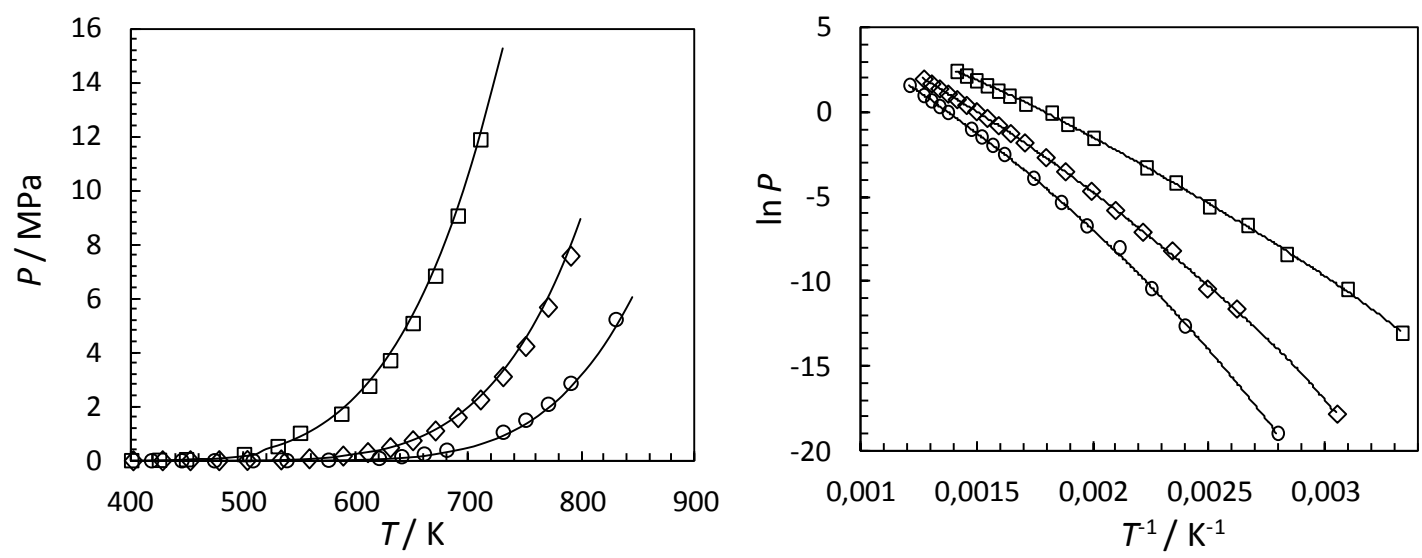

Figure 2. Vapour-pressure curves of $n \mathrm{C}_{16}(\square), n \mathrm{C}_{24}(\diamond)$ and $n \mathrm{C}_{32}(\bigcirc)$ using the correlated SAFT-VR Mie molecular parameters. 


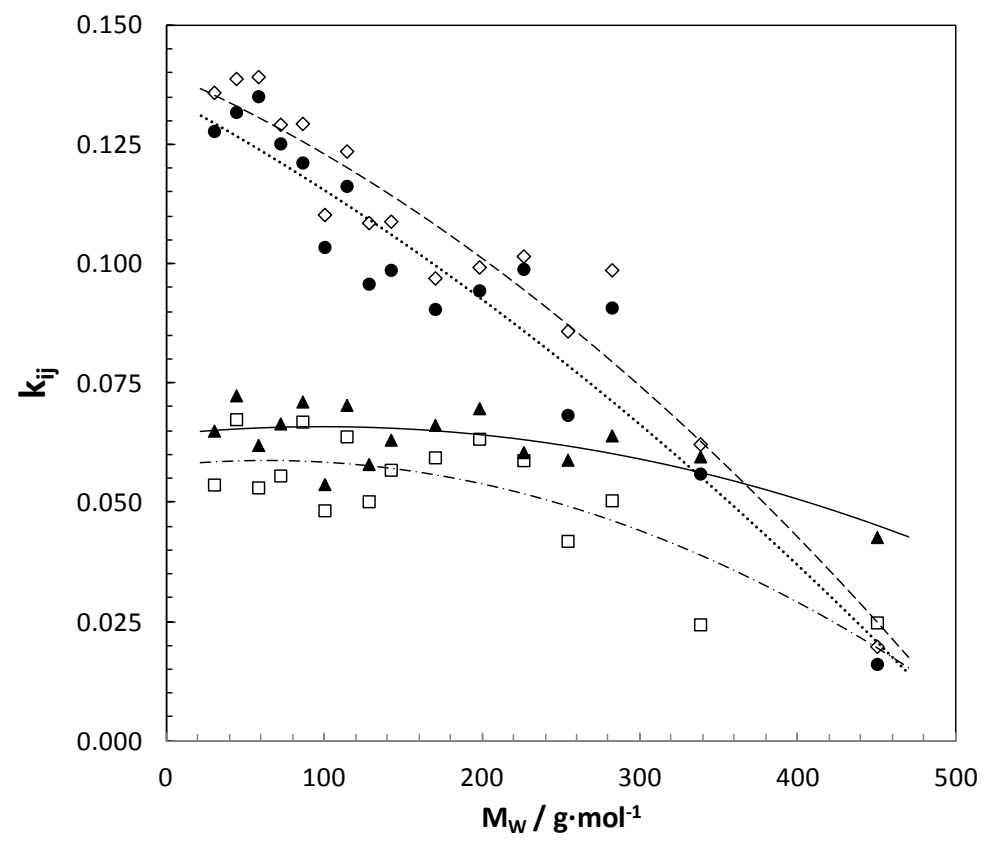

Figure 3. Binary interaction parameters of $n$-alkanes $+\mathrm{CO}_{2}$ binary system and their trend curves for the SRK $(\diamond$, dashed lines), PR $(\bullet$, dotted line), PC-SAFT $(\triangle$, continuous line) and SAFT-VR Mie ( $\square$, dotdashed line) EoS. 

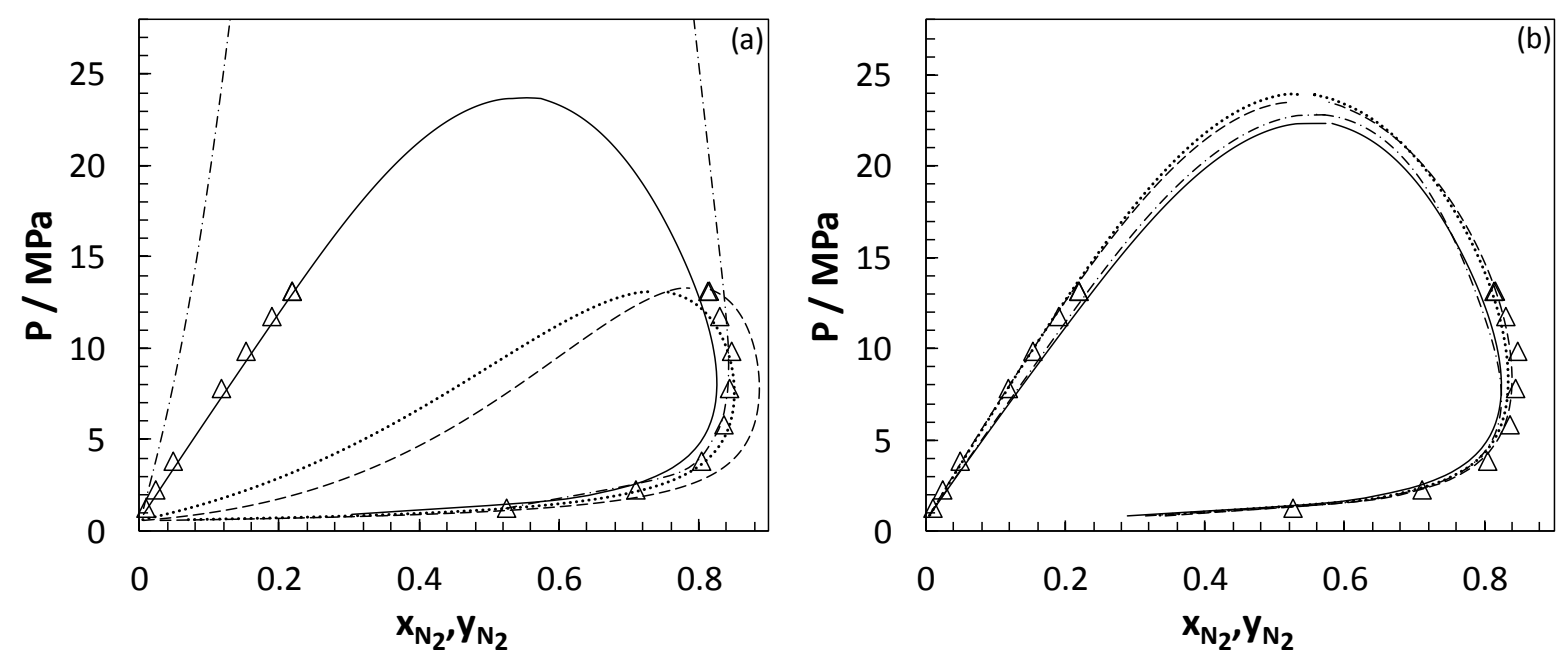

Fig 4. Pressure-composition diagrams of the $\mathrm{CO}_{2}+\mathrm{N}_{2}$ system at 218K. Experimental data $(\triangle)$ [45]. The SRK (dashed lines), PR (dotted line), PC-SAFT (continuous line) and SAFT-VR Mie (dot-dashed line) EoS with $k_{i j}=0$ (a) and with regressed $k_{i j}(\mathrm{~b})$. 


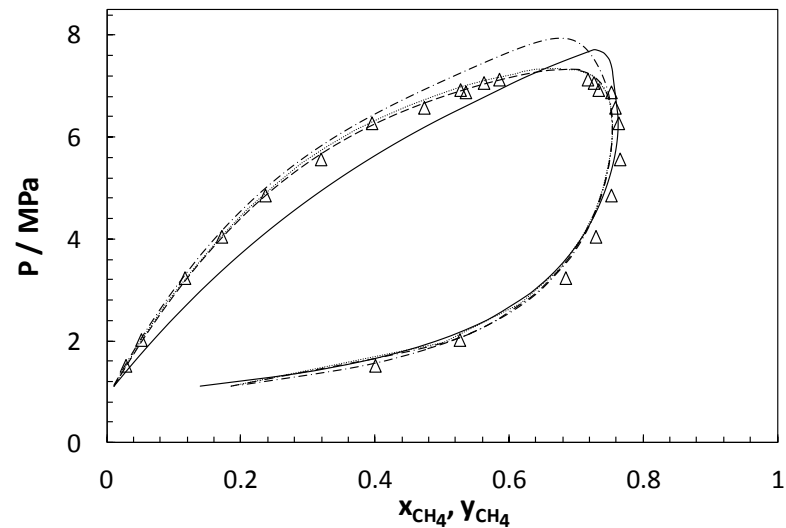

Fig 5. Pressure-composition diagram of the $\mathrm{CH}_{4}+\mathrm{CO}_{2}$ system at 230K. Comparison between experimental data $(\triangle)[46]$ and phase equilibrium calculated by SRK (dashed lines), PR (dotted line), PC-SAFT (continuous line) and SAFT-VR Mie (dot-dashed line) EoS using regressed $k_{i j}$. 

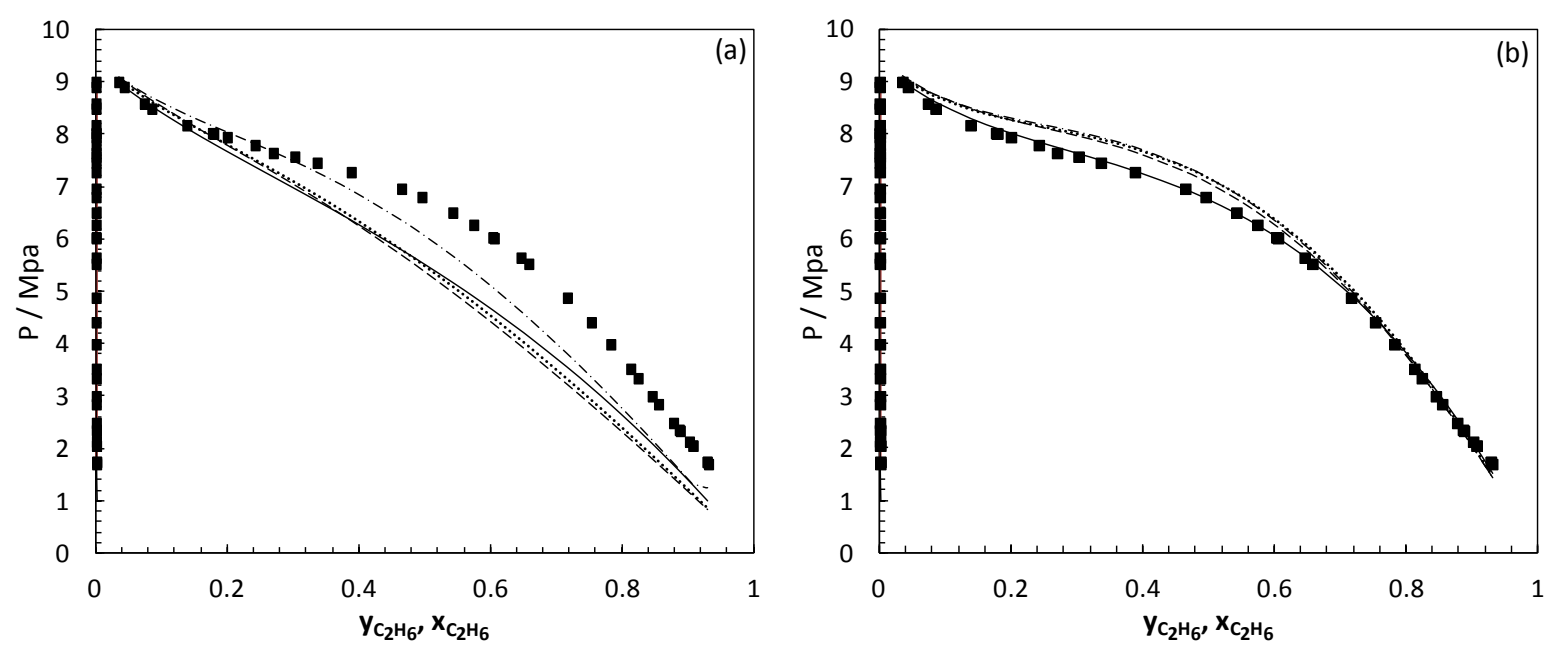

Fig 6. Pressure-composition diagrams of the $\mathrm{C}_{2} \mathrm{H}_{6}+$ Ar system at 116K. Experimental data (ש) [47]. The SRK (dashed lines), PR (dotted line), PC-SAFT (continuous line) and SAFT-VR Mie (dot-dashed line) EoS with $k_{i j}=0\left(\right.$ a) and with regressed $k_{i j}(\mathbf{b})$. 


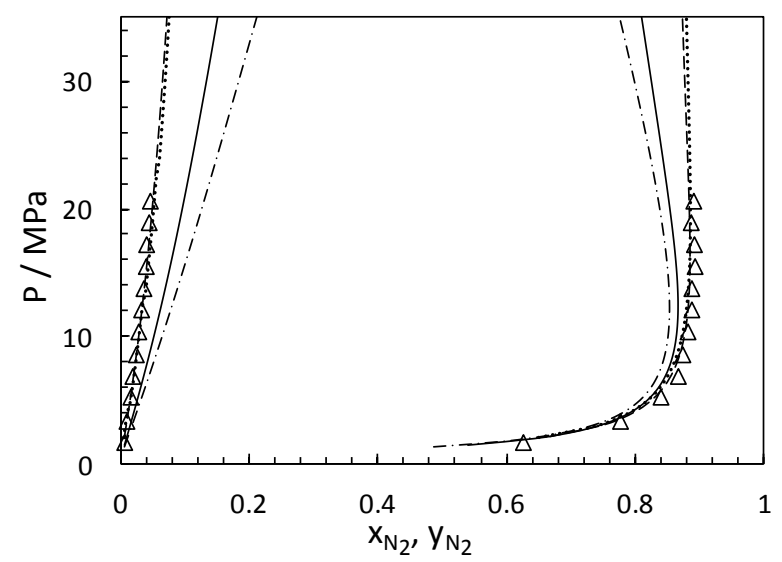

Fig 7. Pressure-composition diagram of the $\mathrm{N}_{2}+\mathrm{H}_{2} \mathrm{~S}$ system at 256K. Comparison between experimental data $(\triangle)$ [48], the SAFT-VR Mie EoS with $\boldsymbol{k}_{i j}=0$ (continuous line) and with regressed $\boldsymbol{k}_{i j}$ (dashed lines) and the PR EoS with $k_{i j}=0$ (dot-dashed line) and with regressed $k_{i j}$ (dotted line). 


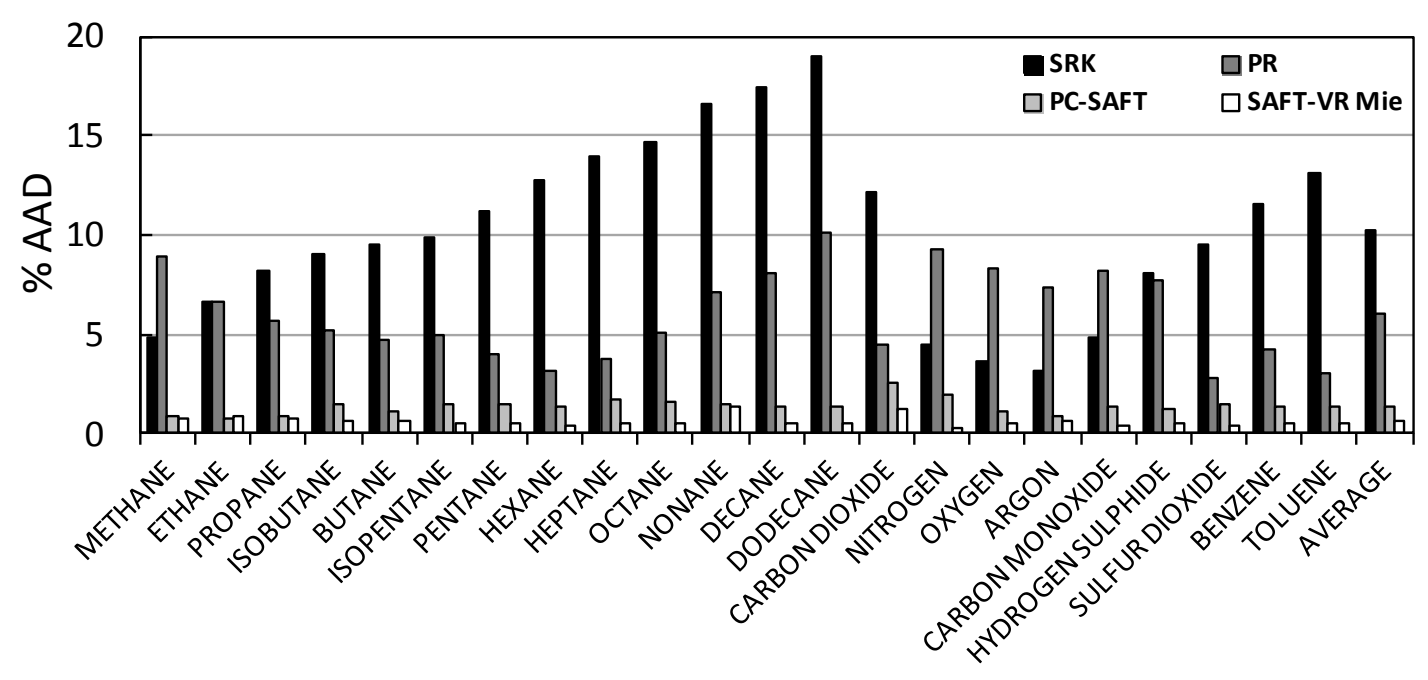

Fig 8. Deviations in the correlated saturated liquid density by SRK (black), PR (dark gray), PC-SAFT (light grey) and SAFT-VR Mie (white) EoS. 


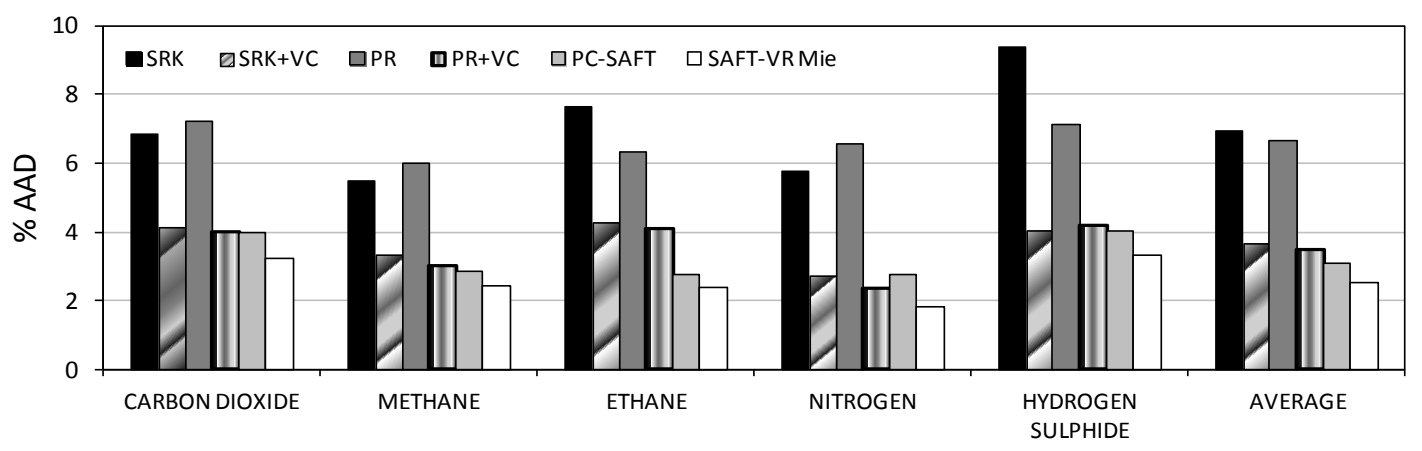

Fig 9. Deviations in the calculated density of binary systems of $\mathrm{CO}_{2}, \mathrm{CH}_{4}, \mathrm{C}_{2} \mathrm{H}_{6}, \mathrm{~N}_{2}$ and $\mathrm{H}_{2} \mathrm{~S}+\mathrm{Comp2}$ by SRK (black), SRK+VC (diagonal grey lines), PR (dark gray), PR+VC (vertical grey lines) PC-SAFT (light grey) and SAFT-VR Mie (white) EoS. 


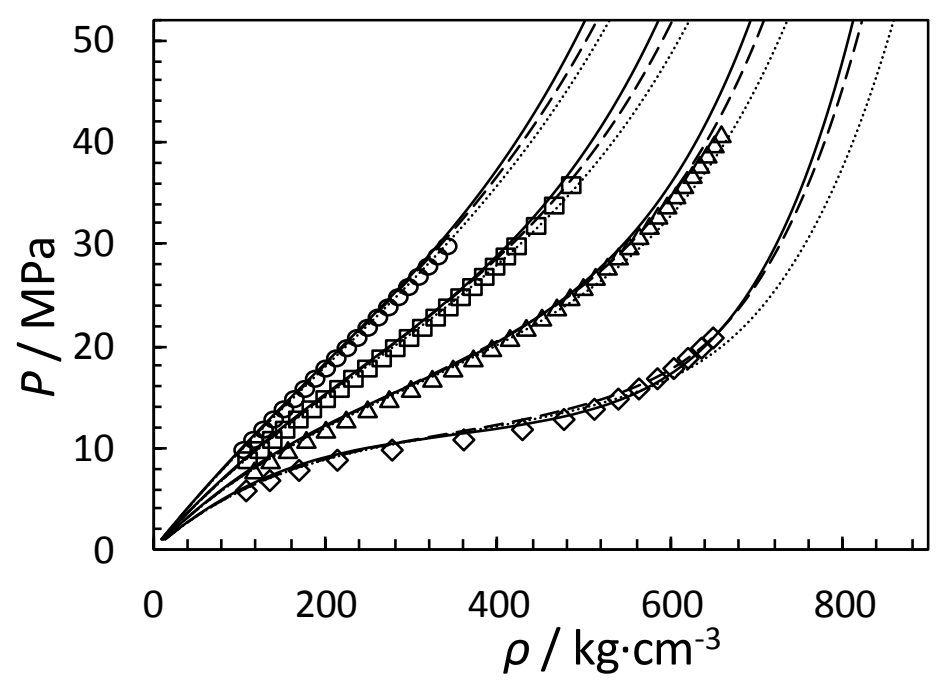

Fig 10. Experimental and calculated densities of the 0.514 mole $\mathrm{CO}_{2}+0.486$ mole $\mathrm{H}_{2} \mathrm{~S}$ using SAFT-VR Mie (continuous lines), PR+Peneloux (dashed lines) and PR (dotted lines) EoS with the regressed $k_{i j}$. Symbols $[49]:(\diamond) 350 \mathrm{~K},(\triangle) 400 \mathrm{~K},(\square) 450 \mathrm{~K}$ and $(O)$ 500K. 


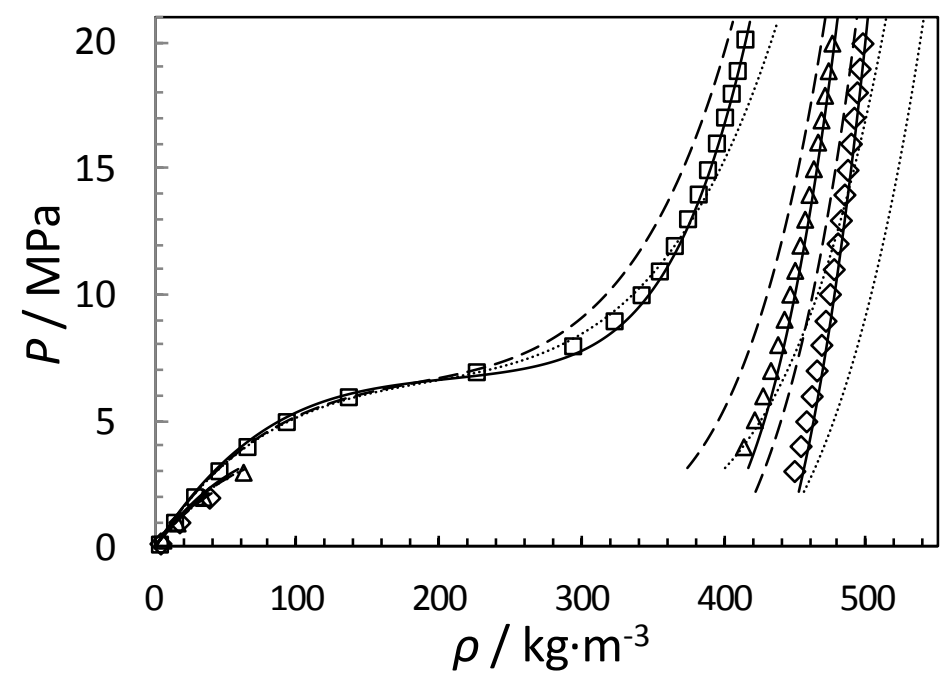

Fig 11. Experimental and calculated densities of the 0.857 mole $_{2} \mathrm{C}_{6}+0.143$ mole $\mathrm{H}_{2} \mathrm{~S}$ using SAFT-VR Mie (continuous lines), SRK+Peneloux (dashed lines) and SRK (dotted lines) EoS with the regressed $\boldsymbol{k}_{i j}$. Symbols $[50]:(\diamond) 268 \mathrm{~K},(\triangle) 283 \mathrm{~K}$ and $(\square) 322 \mathrm{~K}$. 


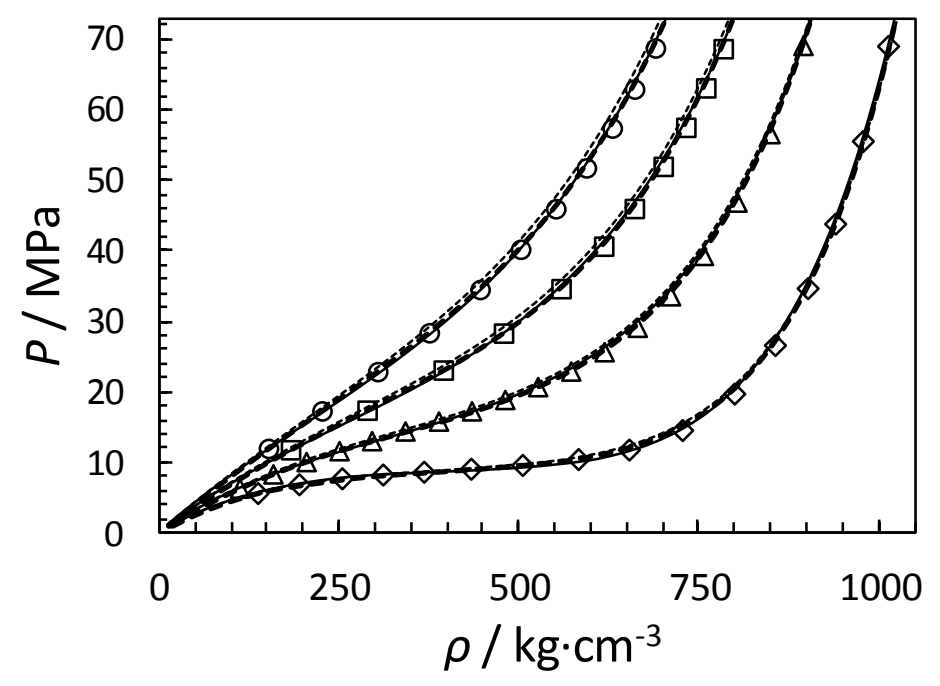

Fig.12. Experimental and calculated densities of the 0.9101 mole $\mathrm{CO}_{2}+0.0899$ mole $\mathrm{N}_{2}$ using PC-SAFT (continuous lines), SRK+Peneloux (dashed lines) and SRK EoS with the regressed $k_{i j}$. Symbols [51]: ( $)$ $300 \mathrm{~K},(\triangle)$ 350K, ( $\square) 400 \mathrm{~K}$ and $(O) 450 \mathrm{~K}$. 


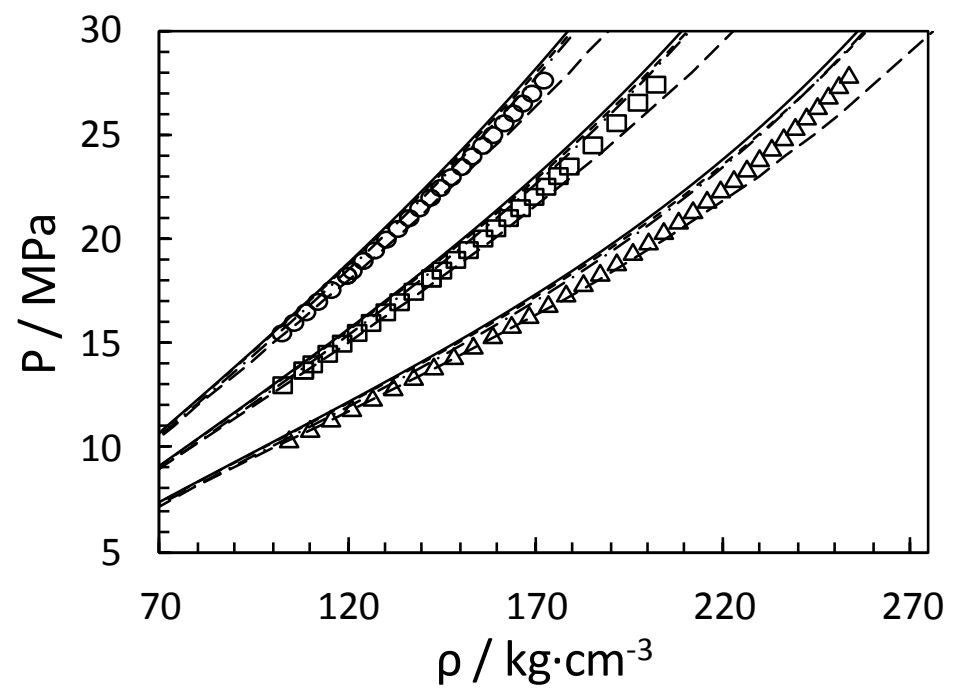

Fig.13. Experimental and calculated densities of the 0.8 mole $\mathrm{CH}_{4}+0.2$ mole $\mathrm{N}_{2}$ using SRK (continuous lines), SRK+Peneloux (doted lines), PR (dashed lines) and PR+Peneloux (dot-dashed line) EoS with the regressed $k_{i j}$. Symbols [52]: $(\triangle)$ 270K, ( $\left.\square\right)$ 313K and (O) 353K. 


\section{Reference}

[1] M. E. Boot-Handford et al., "Carbon capture and storage update," Energy Environ. Sci., vol. 7, pp. 130$189,2014$.

[2] É. Clapeyron, "Puissance motrice de la chaleur,” J. l’ Ec. Polytech., vol. 14, no. 153, 1834.

[3] J. D. van Der Waals, "Over de Continuiteit van den Gas-en Vloeistoftoestand," University of Leiden, 1873.

[4] G. Soave, "Equilibrium constants from a modified Redkh-Kwong equation of state," J. Chem. Eng. Sci., vol. 27, no. 6, pp. 1197-1203, 1972.

[5] D. Y. Peng and D. B. Robinson, "A New Two-Constant Equation of State," Ind. Eng. Chem. Fundam., vol. 15, no. 1, pp. 59-64, Feb. 1976.

[6] S. Dufal, T. Lafitte, A. Galindo, G. Jackson, and A. J. Haslam, "Developing intermolecular-potential models for use with the SAFT-VRMie equation of state," AIChE J., vol. 61, no. 9, pp. 2891-2912, Sep. 2015 .

[7] A. Maghari and L. Hosseinzadeh-Shahri, "Evaluation of the performance of cubic equations of state in predicting the regularities in dense fluids," Fluid Phase Equilib., vol. 206, no. 1-2, pp. 287-311, Apr. 2003.

[8] A. Péneloux, E. Rauzy, and R. Fréze, "A consistent correction for Redlich-Kwong-Soave volumes," Fluid Phase Equilib., vol. 8, no. 1, 1982.

[9] K. Pedersen, P. Christensen, and J. Shaikh, Phase behavior of petroleum reservoir fluids, CRC Press. Boca Raton, FL, 2007.

[10] C. Tsonopoulos and J. L. Heidman, "From Redlich-Kwong to the present," Fluid Phase Equilib., vol. 24, no. 1-2, pp. 1-23, Jan. 1985.

[11] W. G. Chapman, K. E. Gubbins, G. Jackson, and M. Radosz, "SAFT: Equation-of-state solution model for associating fluids," Fluid Phase Equilib., vol. 52, pp. 31-38, Dec. 1989.

[12] S. H. Huang and M. Radosz, "Equation of state for small, large, polydisperse, and associating molecules," Ind. Eng. Chem. Res., vol. 29, no. 11, pp. 2284-2294, Nov. 1990.

[13] T. Kraska and K. E. Gubbins, "Phase Equilibria Calculations with a Modified SAFT Equation of State. 2. Binary Mixtures of n -Alkanes, 1-Alkanols, and Water," Ind. Eng. Chem. Res., vol. 35, no. 12, pp. 4738-4746, Jan. 1996.

[14] A. Gil-Villegas, A. Galindo, P. J. Whitehead, S. J. Mills, G. Jackson, and A. N. Burgess, "Statistical associating fluid theory for chain molecules with attractive potentials of variable range," J. Chem. Phys., vol. 106, no. 10, p. 4168, 1997.

[15] F. J. Blas and L. F. Vega, "Thermodynamic behaviour of homonuclear and heteronuclear Lennard-Jones chains with association sites from simulation and theory," Mol. Phys., vol. 92, no. 1, pp. 135-150, Sep. 1997.

[16] J. Gross and G. Sadowski, "Perturbed-Chain SAFT: An Equation of State Based on a Perturbation Theory for Chain Molecules," Ind. Eng. Chem. Res., vol. 40, no. 4, pp. 1244-1260, Feb. 2001.

[17] J. Gross and G. Sadowski, "Application of the Perturbed-Chain SAFT Equation of State to Associating Systems,” vol. 41, pp. 5510-5515, 2002.

[18] G. M. Kontogeorgis, E. C. Voutsas, I. V. Yakoumis, and D. P. Tassios, "An Equation of State for Associating Fluids,” Ind. Eng. Chem. Res., vol. 35, no. 11, pp. 4310-4318, Jan. 1996.

[19] W. Yan, F. Varzandeh, and E. H. Stenby, "PVT modeling of reservoir fluids using PC-SAFT EoS and Soave-BWR EoS,” Fluid Phase Equilib., vol. 386, pp. 96-124, 2015.

[20] T. Lafitte et al., "Accurate statistical associating fluid theory for chain molecules formed from Mie segments.," J. Chem. Phys., vol. 139, no. 15, p. 154504, Oct. 2013. 
[21] S. Dufal et al., "The A in SAFT: developing the contribution of association to the Helmholtz free energy within a Wertheim TPT1 treatment of generic Mie fluids," Mol. Phys., vol. 113, no. 9-10, pp. 948-984, May 2015.

[22] N. I. Diamantonis, G. C. Boulougouris, E. Mansoor, D. M. Tsangaris, and I. G. Economou, "Evaluation of Cubic, SAFT, and PC-SAFT Equations of State for the Vapor-Liquid Equilibrium Modeling of CO 2 Mixtures with Other Gases," Ind. Eng. Chem. Res., vol. 52, no. 10, pp. 3933-3942, Mar. 2013.

[23] J. M. Prausnitz, R. N. Lichtenthaler, and E. G. de Azevedo, Molecular Thermodynamics of Fluid-Phase Equilibria, 3rd ed. New Jersey, 1999.

[24] J. L. Daridon, H. Saint-Guirons, B. La Courette, P. Xans, and C. Leibovici, “A generalized process for phase equilibrium calculation with cubic equations of state," Int. J. Thermophys., vol. 14, no. 5, pp. 1101-1108, 1993.

[25] D. Peng and D. Robinson, "The characterization of the heptanes and heavier fractions for the GPA PengRobinson programs," Gas Process. Assoc., vol. RR-28, 1978.

[26] J. O. Valderrama and M. Alfaro, "Liquid volumes from generalized cubic equations of state: Take it with care,” Oil Gas Sci. Technol., vol. 55, no. 5, pp. 523-531, 2000.

[27] J.-N. Jaubert, R. Privat, Y. L. E. Guennec, and L. Coniglio, "Note on the properties altered by application of a Péneloux-type volume translation to an equation of state," Fluid Phase Equilib., vol. 419, pp. 88-95, 2016.

[28] J. A. Barker and D. Henderson, "Perturbation Theory and Equation of State for Fluids: The Square-Well Potential," J. Chem. Phys., vol. 47, no. 8, p. 2856, 1967.

[29] J. A. Barker and D. Henderson, "Perturbation Theory and Equation of State for Fluids. II. A Successful Theory of Liquids," J. Chem. Phys., vol. 47, no. 11, p. 4714, 1967.

[30] S. S. Chen and A. Kreglewski, "Applications of the Augmented van der Waals Theory of Fluids.: I. Pure Fluids," Berichte der Bunsengesellschaft für Phys. Chemie, vol. 81, no. 10, pp. 1048-1052, Oct. 1977.

[31] F. Tumakaka and G. Sadowski, "Application of the Perturbed-Chain SAFT equation of state to polar systems,” Fluid Phase Equilib., vol. 217, no. 2, pp. 233-239, Mar. 2004.

[32] T. Lafitte et al., "Accurate statistical associating fluid theory for chain molecules formed from Mie segments," J. Chem. Phys., vol. 139, 2013.

[33] A. G. Perez, A. Valtz, C. Coquelet, P. Paricaud, and A. Chapoy, "Experimental and modelling study of the densities of the hydrogen sulphide + methane mixtures at 253, 273 and $293 \mathrm{~K}$ and pressures up to 30 MPa," Fluid Phase Equilib., vol. 427, pp. 371-383, 2016.

[34] K. Schou Pedersen and C. Hasdbjerg, "PC-SAFT Equation of State Applied to Petroleum Reservoir Fluids," SPE Annu. Tech. Conf. Exhib., vol. 1, no. 4, pp. 1-10, 2007.

[35] G. Kontogeorgis and G. Folas, Thermodynamic Models for Industrial Applications From Classical and Advanced Mixing Rules to Association Theories, 1st ed. Chippenham, Wiltshire: CPI Antony Rowe Ltd, 2010 .

[36] V. Diky, C. D. Muzny, E. W. Lemmon, R. D. Chirico, and M. Frenkel, "NIST Standard Reference Database 103a: NIST ThermoData Engine: Version 2.7 - Pure Compounds,” 2007.

[37] M. M. Lemmon and M. Huber, "NIST Standard Reference Database 23: Reference Fluid Thermodynamic and Transport Properties Database (REFPROP): Version 9.1." Gaithersburg: National Institute of Standards and Technology, Standard Reference Data Program, 2012.

[38] P. H. V. Konynenburg and R. L. Scott, "Critical Lines and Phase Equilibria in Binary Van Der Waals Mixtures,” Philos. Trans. R. Soc. A Math. Phys. Eng. Sci., vol. 298, no. 1442, pp. 495-540, Dec. 1980.

[39] N. K. Muirbrook and J. M. Prausnitz, "Multicomponent vapor-liquid equilibria at high pressures: Part I. Experimental study of the nitrogen-oxygen-carbon dioxide system at $0^{\circ} \mathrm{C}$," $A I C h E J$., vol. 11, no. 6, pp. 1092-1096, 1965. 
[40] A. A. Kukarni, B. Y. Zarah, K. D. Luks, and J. P. Kohn, "Phase-equilbriums behavior of system carbon dioxide-n-decane at low temperatures,” J. Chem. Eng. Data, vol. 19, no. 1, pp. 92-94, Jan. 1974.

[41] J. van der Steen, T. W. de Loos, and J. de Swaan Arons, "The volumetric analysis and prediction of liquid-liquid-vapor equilibria in certain carbon dioxide + n-alkane systems," Fluid Phase Equilib., vol. 51, pp. 353-367, Nov. 1989.

[42] S. Langè, M. Campestrini, and P. Stringari, "Phase behavior of system methane + hydrogen sulfide," AIChE J., vol. 7, no. PART 1, pp. 405-410, May 2016.

[43] A. J. Davenport and J. S. Rowlinson, "The solubility of hydrocarbons in liquid methane.," Trans. Faraday Soc., vol. 59, p. 78, 1963.

[44] R. Span and W. Wagner, "A New Equation of State for Carbon Dioxide Covering the Fluid Region from the Triple-Point Temperature to $1100 \mathrm{~K}$ at Pressures up to $800 \mathrm{MPa}$," J. Phys. Chem. Ref. Data, vol. 25, no. 6, p. $1509,1996$.

[45] M. Yorizane, S. Yoshimura, H. Masuoka, and M. Nakamura, "Prediction of high pressure vapor-liquid equilibria for multicomponent systems by the bwr equation of state," J. Chem. Eng., vol. 4, pp. 10-16, 1971.

[46] F. A. Somait and A. J. Kidnay, "Liquid-vapor equilibriums at $270.00 \mathrm{~K}$ for systems containing nitrogen, methane, and carbon dioxide," J. Chem. Eng. Data, vol. 23, no. 4, pp. 301-305, Oct. 1978.

[47] I. M. Elshayal and B. C. Lu, "Vapour-liquid equilibria in the argon-ethane and argon-methaneethane systems at 155 K," Cryogenics (Guildf)., vol. 11, no. 4, pp. 285-289, Aug. 1971.

[48] G. J. Besserer and D. B. Robinson, "Equilibrium-phase properties of nitrogen-hydrogen sulfide system," J. Chem. Eng. Data, vol. 20, no. 2, pp. 157-161, Apr. 1975.

[49] C. Liu, "Experimental Densities, Entropies, and Energies for Pure H2S and Equimolar Mixtures of $\mathrm{H} 2 \mathrm{~S} / \mathrm{CH} 4$ and H2S/CO2 between 300 and $500 \mathrm{~K}$," Texas A\&M University, 1985.

[50] F. Rivollet, C. Jarne, and D. Richon, "P $\rho$ T and VLE for Ethane + Hydrogen Sulfide from ( 254.05 to 363 . 21 ) K at Pressures up to $20 \mathrm{MPa}$," J. Chem. Eng. Data, vol. 8, pp. 1883-1890, 2005.

[51] H. B. Brugge, J. C. Holste, K. R. Hall, B. E. Gammon, and K. N. Marsh, "Densities of Carbon Dioxide + Nitrogen from $225 \mathrm{~K}$ to $450 \mathrm{~K}$ at Pressures up to $70 \mathrm{MPa}$," J. Chem. Eng. Data, vol. 42, no. 5, pp. 903907, Sep. 1997.

[52] M. Jaeschke and H. M. Hinze, "Determination of the Real Gas Behaviour of Methane and Nitrogen and Their Mixtures in the Temperature Range from $270 \mathrm{~K}$ to $353 \mathrm{~K}$ and at Pressures Up To $30 \mathrm{MPa}$," Fortschr-Ber. VDI, R. 6, nr, 262, 1991. 